\title{
Kinetically Controlled Self-Assembly of Binary Polymer- Grafted Nanocrystals into Ordered Superstructures via Solvent Vapor Annealing
}

Yi Wang ${ }^{1}$, Jun Chen ${ }^{1}$, Chenhui Zhu ${ }^{2}$, Baixu Zhu ${ }^{1}$, Soojin Jeong ${ }^{1}$, Yi Yi ${ }^{1}$, Yang Liu ${ }^{1}$, Joshua Fiadorwu ${ }^{3}$, Peng $\mathrm{He}^{3}$, Xingchen $\mathrm{Ye}^{1^{*}}$

${ }^{1}$ Department of Chemistry, Indiana University, Bloomington, Indiana 47405, USA

${ }^{2}$ Advanced Light Source, Lawrence Berkeley National Laboratory, Berkeley, California 94720, USA

${ }^{3}$ Department of Chemistry, North Carolina Agricultural and Technical State University, Greensboro, North Carolina 27411, USA

*Correspondence should be addressed to X.Y. (xingye@indiana.edu). 


\section{Experimental Section}

Chemicals. Unless otherwise noted, reagents were used as received without further purification. Styrene ( $\geq 99 \%$ ), ethyl $\alpha$-bromoisobutyrate (EBIB, 98\%), copper(II) bromide (99\%), tin(II) 2ethylhexanoate $\quad(\mathrm{Sn}(\mathrm{EH}) 2, \quad 92.5-100.0 \%), \quad$ diethylenetriamine $\quad$ (DETA, 99\%), pentaethylenehexamine (PEHA, technical grade), triethylamine (NEt3, $\geq 99.5 \%$ ), $N, N$ dimethylformamide (DMF, anhydrous, $99.8 \%$ ), iron(III) chloride hexahydrate $\left(\mathrm{FeCl}_{3} \cdot 6 \mathrm{H}_{2} \mathrm{O}, 97 \%\right)$, oleic acid (OA, 90\%), and tris[2-(dimethylamino)ethyl]amine (Me6TREN, 97\%) were purchased from Sigma Aldrich. Calcium hydride (90-95\%, 2 mm \& down) were purchased from Alfa Aesar. Sodium oleate $(97 \%)$ and tri- $n$-octylamine (TOA, $>97.0 \%$ ) were purchased from TCI America. 1-Hexadecene (HDE, 92\%) and 1-octadecene (ODE, 90\%) were purchased from Acros Organics. Styrene was extracted with $10 \mathrm{wt} \%$ sodium hydroxide solution to remove inhibitors and distilled with $\mathrm{CaH}_{2}$ under vacuum.

Synthesis of PS-DETA and PS-PEHA. PS-DETA and PS-PEHA were synthesized using a twostep reaction (Scheme S1). In the first step, bromine-terminated polystyrene (PS-Br) was synthesized by using activators regenerated by electron transfer for atom transfer radical polymerization (ARGET ATRP). ${ }^{1}$ In the second step, the bromine end group was converted to a multidentate nitrogen-containing ligand.

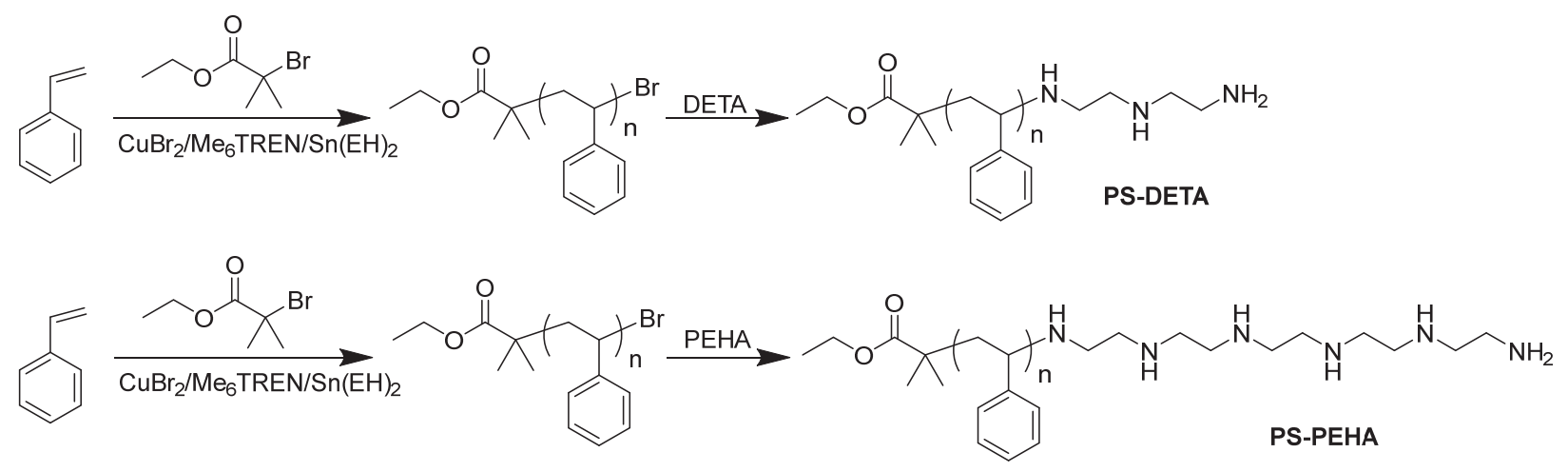

Scheme S1. Synthesis of PS-DETA and PS-PEHA. 
(1) Synthesis of PS-Br. In a typical synthesis of PS-Br with a molecular weight greater than 5 $\mathrm{kDa}$, styrene (43.6 mmol), EBIB (436 $\mu \mathrm{mol}), \mathrm{CuBr}_{2}(4 \mu \mathrm{mol})$ and $\mathrm{Me}_{6}$ TREN $(44 \mu \mathrm{mol})$ were added at room temperature to a round-bottom flask. After purging with $\mathrm{N}_{2}$ for $30 \mathrm{~min}, \mathrm{Sn}(\mathrm{EH})_{2}$ (44 $\mu \mathrm{mol}$ ) was injected and the reaction solution was raised to $90{ }^{\circ} \mathrm{C}$ under stirring. The reaction was terminated after 12-18 hours by exposure to air while cooling the reaction flask with an ice bath. To synthesize $2.7 \mathrm{kDa}$ PS-Br, styrene (43.6 mmol), anhydrous toluene (5 mL), EBIB (1.45 mmol), $\mathrm{CuBr}_{2}(15 \mu \mathrm{mol})$ and $\mathrm{Me}_{6} \mathrm{TREN}(145 \mu \mathrm{mol})$ were added to a round-bottom flask. After purging with $\mathrm{N}_{2}$ for $30 \mathrm{~min}, \mathrm{Sn}(\mathrm{EH})_{2}(145 \mu \mathrm{mol})$ was injected and the reaction solution was raised to $90^{\circ} \mathrm{C}$ under stirring. The reaction was terminated after 22 hours by exposure to air while cooling the reaction flask with an ice bath. The reaction mixture was diluted with THF and precipitated using methanol. Afterwards, polystyrene was collected via vacuum filtration followed by redissolution in THF. To remove residual copper-based catalysts, the THF solution of polystyrene was mixed with neutral $\mathrm{Al}_{2} \mathrm{O}_{3}$ and stirred overnight followed by removing the $\mathrm{Al}_{2} \mathrm{O}_{3}$ powder using vacuum filtration. Polystyrene was precipitated again with methanol, vacuum filtered and dried inside a vacuum oven at $40{ }^{\circ} \mathrm{C}$ overnight. A representative ${ }^{1} \mathrm{H}$ NMR spectrum of $\mathrm{PS}-\mathrm{Br}$ is shown in Figure S1. GPC measurement results of PS-Br are presented in Figure S4a.

(2) Conversion of the bromine end group to DETA or PEHA. DETA and PEHA-terminated PS were synthesized based on a previously reported method with modifications. ${ }^{2}$ In a typical reaction, PS-Br $(0.2 \mathrm{mmol})$, DETA or PEHA $(10 \mathrm{mmol})$ and triethylamine $(20 \mathrm{mmol})$ were dissolved into DMF. The reaction mixture was stirred for $72 \mathrm{~h}$ at room temperature. Afterwards, PS-DETA (or PS-PEHA) was precipitated with methanol, collected by vacuum filtration. Polymers were purified three more times by dissolution in THF and precipitation in methanol before being dried inside a vacuum oven at $40{ }^{\circ} \mathrm{C}$ overnight. Representative ${ }^{1} \mathrm{H}$ NMR spectra of PS-DETA and PS-PEHA are shown in Figure S2.

Synthesis of oleate-capped $\mathrm{Fe}_{3} \mathrm{O}_{4}$ NCs. $\mathrm{Fe}_{3} \mathrm{O}_{4} \mathrm{NCs}$ were synthesized according to a previously reported method. ${ }^{3}$ To prepare the iron oleate precursor, $21.6 \mathrm{~g}$ of $\mathrm{FeCl}_{3} \cdot 6 \mathrm{H}_{2} \mathrm{O}$ and $73.0 \mathrm{~g}$ of sodium oleate were dissolved into a mixture of ultrapure water $(80 \mathrm{~mL})$, ethanol $(80 \mathrm{~mL})$ and hexane $(160$ $\mathrm{mL}$ ), and the resulting solution was stirred at $68{ }^{\circ} \mathrm{C}$ for $4 \mathrm{~h}$. The dark red layer containing iron oleate was washed with warm water for three times using a separatory funnel. Finally, iron oleate was dried under vacuum to remove residual hexane and water. 
To synthesize $5.4 \mathrm{~nm} \mathrm{Fe}_{3} \mathrm{O}_{4} \mathrm{NCs}, 9 \mathrm{~g}$ of iron oleate, $30 \mathrm{~mL}$ of 1-hexadecene, $30 \mathrm{~mL}$ of 1octadecene and $1.5 \mathrm{~mL}$ of oleic acid were added to a $125 \mathrm{~mL}$ three-neck round bottom flask. The reaction mixture was evacuated at $100{ }^{\circ} \mathrm{C}$ for $30 \mathrm{~min}$, heated to $300{ }^{\circ} \mathrm{C}$ at $3.3^{\circ} \mathrm{C} / \mathrm{min}$ under $\mathrm{N}_{2}$ flow and kept at $300{ }^{\circ} \mathrm{C}$ for $1 \mathrm{~h} .7 .4 \mathrm{~nm}$ and $8.7 \mathrm{~nm} \mathrm{Fe} 3 \mathrm{O}_{4} \mathrm{NCs}$ were synthesized by using the same method, except at higher reaction temperatures (Table S1). The reaction flask was cooled naturally to room temperature. $\mathrm{Fe}_{3} \mathrm{O}_{4} \mathrm{NCs}$ were purified through three cycles of acetone precipitation followed by redispersion in hexane. NCs were finally dissolved in toluene.

To synthesize $13.5 \mathrm{~nm} \mathrm{Fe} \mathrm{O}_{4} \mathrm{NCs}, 9 \mathrm{~g}$ of iron oleate, $40 \mathrm{~mL}$ of 1-octadecene, $20 \mathrm{~mL}$ of tri- $n$ octylamine and $1.5 \mathrm{~mL}$ of oleic acid were loaded into a $125 \mathrm{~mL}$ three-neck round bottom flask. The reaction mixture was evacuated at $100{ }^{\circ} \mathrm{C}$ for $30 \mathrm{~min}$, heated to $330^{\circ} \mathrm{C}$ at $3.3{ }^{\circ} \mathrm{C} / \mathrm{min}$ under $\mathrm{N}_{2}$ flow and maintained at $330{ }^{\circ} \mathrm{C}$ for $40 \mathrm{~min} .16 .8 \mathrm{~nm}$ and $20.6 \mathrm{~nm} \mathrm{Fe} 3 \mathrm{O}_{4} \mathrm{NCs}$ were synthesized using the same protocol, except at higher reaction temperatures (Table S1). After the reaction solution is cooled to room temperature, $\mathrm{Fe}_{3} \mathrm{O}_{4} \mathrm{NCs}$ were purified through three rounds of precipitation with isopropanol followed by redispersion in hexane. Finally, NCs were dissolved in toluene.

Table S1. Reaction conditions for $\mathrm{Fe}_{3} \mathrm{O}_{4} \mathrm{NCs}$.

\begin{tabular}{ccccc}
\hline NC size & $\begin{array}{c}\text { Iron } \\
\text { oleate }\end{array}$ & Solvent & OA & Temperature $\left({ }^{\circ} \mathbf{C}\right)$ \\
\hline $5.4 \mathrm{~nm}$ & $9 \mathrm{~g}$ & $30 \mathrm{~mL} \mathrm{HDE} / 30 \mathrm{~mL} \mathrm{ODE}$ & $1.5 \mathrm{~mL}$ & 300 \\
$7.4 \mathrm{~nm}$ & $9 \mathrm{~g}$ & $15 \mathrm{~mL} \mathrm{HDE} / 45 \mathrm{~mL} \mathrm{ODE}$ & $1.5 \mathrm{~mL}$ & 310 \\
$8.7 \mathrm{~nm}$ & $9 \mathrm{~g}$ & $60 \mathrm{~mL} \mathrm{ODE}$ & $1.5 \mathrm{~mL}$ & 320 \\
$13.5 \mathrm{~nm}$ & $9 \mathrm{~g}$ & $40 \mathrm{~mL} \mathrm{ODE} / 20 \mathrm{~mL}$ TOA & $1.5 \mathrm{~mL}$ & 330 \\
$16.8 \mathrm{~nm}$ & $9 \mathrm{~g}$ & $30 \mathrm{~mL} \mathrm{ODE} / 30 \mathrm{~mL}$ TOA & $1.5 \mathrm{~mL}$ & 343 \\
$20.6 \mathrm{~nm}$ & $9 \mathrm{~g}$ & $20 \mathrm{~mL} \mathrm{ODE} / 40 \mathrm{~mL} \mathrm{TOA}$ & $1.5 \mathrm{~mL}$ & 353 \\
\hline
\end{tabular}

Ligand exchange with PS-DETA and PS-PEHA. To ensure successful ligand exchange and high polymer grafting densities, an excess of PS-DETA (or PS-PEHA) ligands were used. Typically, $330 \mathrm{mg}$ of $8.2 \mathrm{kDa}$ PS-DETA (or $495 \mathrm{mg}$ of $5.5 \mathrm{kDa}$ PS-PEHA or $250 \mathrm{mg}$ of $2.7 \mathrm{kDa}$ PS-PEHA) 
was dissolved in $16 \mathrm{~mL}$ of THF, to which $4 \mathrm{~mL}$ of $\mathrm{Fe}_{3} \mathrm{O}_{4} \mathrm{NC}$ solution $(5 \mathrm{mg} / \mathrm{mL}$ in toluene) was added. Following sonication for $5 \mathrm{~s}$, this solution mixture was left undisturbed for $48 \mathrm{~h}$. PS-grafted $\mathrm{Fe}_{3} \mathrm{O}_{4} \mathrm{NCs}$ were purified via precipitation with heptane followed by centrifugation at $4000 \mathrm{rpm}$ for $2 \mathrm{~min}$. The pellet was re-dispersed in THF and this purification procedure was repeated four more times to remove unbound polystyrene and oleate ligands. Finally, PS-grafted NCs were dispersed in toluene and filtered through a $0.2 \mu \mathrm{m}$ polytetrafluoroethylene (PTFE) syringe filter.

Preparation of PGNC thin films and solvent vapor annealing. PGNC thin films were prepared by spin-coating $20 \mathrm{uL}$ of toluene solution containing binary $\mathrm{Fe}_{3} \mathrm{O}_{4} \mathrm{PGNCs}$ at $1500 \mathrm{rpm}$ for $45 \mathrm{~s}$ onto a silicon substrate $\left(1 \times 1 \mathrm{~cm}^{2},<100>\right.$ oriented $)$. The total mass concentration of PGNCs was $20 \mathrm{mg} / \mathrm{mL}$ and the number ratio between small and large PGNCs was 13:1 unless otherwise noted. Silicon substrates were cleaned by sonication in an isopropanol bath for $40 \mathrm{~min}$ before use.

The workflow of solvent vapor annealing (SVA) is illustrated in Scheme S2. As-spun PGNC film was placed inside a home-built SVA apparatus which combined a continuous flow of saturated solvent vapor with a $\mathrm{N}_{2}$ diluent to access variable partial vapor pressures. The first $\mathrm{N}_{2}$ line (denoted as Channel 1) is connected to a $\mathrm{CHCl}_{3}$ solvent reservoir to allow a saturated solvent vapor to exit. The second $\mathrm{N}_{2}$ line (denoted as Channel 2) is employed to dilute the saturated solvent vapor coming out of Channel 1 before entering the SVA chamber $\left(7.7 \times 7.7 \times 1 \mathrm{~cm}^{3}\right)$.

In a typical SVA experiment, the chamber was first flushed with pure $\mathrm{N}_{2}$ at 200 standard cubic centimeters per minute $(\mathrm{sccm})$ for $3 \mathrm{~min}$ to remove air and moisture. Next, solvent vapor was introduced into the SVA chamber to swell the film and to initiate PGNC assembly. The solvent vapor pressure was varied by controlling the $\mathrm{N}_{2}$ flow rates of Channel 1 and Channel 2 using two mass flow controllers (MFCs) while maintaining the total flow rate to be 100 sccm. The swollen and dry film thicknesses were monitored using a spectroscopic reflectometer (Filmetrics F20). SVA was terminated by stopping the flow of solvent infused $\mathrm{N}_{2}$ (i.e., Channel 1) while increasing the pure $\mathrm{N}_{2}$ flow (i.e., Channel 2) to $200 \mathrm{sccm}$ to rapidly deswell the PGNC film

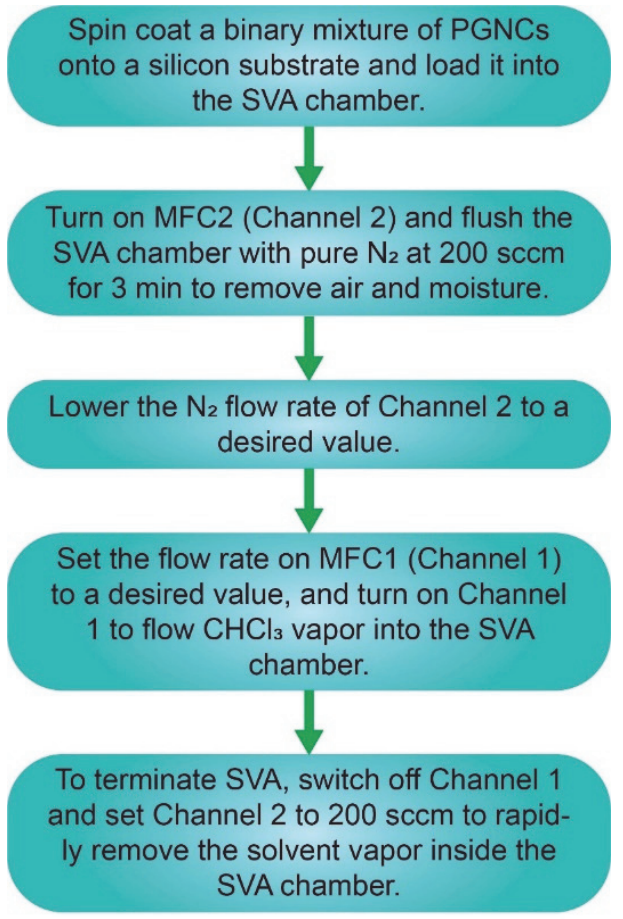

Scheme S2. A typical SVA experimental workflow. 
facilitated by the high volatility of $\mathrm{CHCl}_{3}$. Additionally, PGNCs were spin-coated onto carboncoated mica substrates and solvent annealed under identical conditions. Afterwards, the PGNC film was floated off mica by dipping the substrate into water. The PGNC film was then collected using a $\mathrm{Cu}$ grid for TEM imaging.

Grazing incidence small-angle X-ray scattering (GISAXS). GISAXS measurements were conducted at beamline 7.3.3 of the Advanced Light Source, Lawrence Berkeley National Laboratory. X-rays $(10 \mathrm{keV})$ with the energy bandwidth $\mathrm{E} / \Delta \mathrm{E}=100$ were used. The beam size was about $300 \mu \mathrm{m}$ vertically and $700 \mu \mathrm{m}$ horizontally. A Pilatus $2 \mathrm{M}$ detector (pixel size: $\sim 172 \mu \mathrm{m}$ ) from Dectris was positioned $3.8 \mathrm{~m}$ away from the sample. The reciprocal space calibration was performed by using a standard sample of silver behenate. For each sample, measurements were done at a series of incident angles ranging from $0.1^{\circ}$ to $0.2^{\circ}$, and the data presented here were acquired at the incident angle of $0.16^{\circ}$. GISXAS images were processed and analyzed using the software packages of NIKA and GIXSGUI. ${ }^{4-5}$ GISAXS horizontal line profiles were obtained along $\mathrm{q}_{\mathrm{z}}=0.031 \AA^{-1}$.

Materials characterization. Gel permeation chromatography (GPC). The average molecular weight and polydispersity index of PS-Br were determined on a Waters Breeze GPC system, equipped with a Waters 1525 binary HPLC pump, a 1500 column heater, a 2414 refractive index detector, and three connected Styragel high resolution columns (HR2, HR4 and HR5, $7.8 \times 300$ $\mathrm{mm}$ ). THF was used as the eluent at a flow rate of $1 \mathrm{~mL} / \mathrm{min}$ during GPC measurements. The instrument was calibrated using commercial polystyrene standards.

Nuclear magnetic resonance (NMR). ${ }^{1} \mathrm{H}$ NMR spectra were recorded in deuterated chloroform at $298 \mathrm{~K}$ using a Varian $600 \mathrm{MHz}$ Inova spectrometer.

Dynamic light scattering (DLS). DLS measurements were carried out on a Zetasizer Nano-ZS system (Malvern) equipped with a He-Ne $633 \mathrm{~nm}$ laser. A diluted chloroform solution of PGNCs $(1 \mathrm{mg} / \mathrm{mL})$ was filtered through a $0.2 \mu \mathrm{m}$ PTFE syringe filter and filled in a quartz cuvette for DLS measurements. The hydrodynamic diameters $\left(D_{h}\right)$ of PGNCs were calculated using the StokesEinstein equation, $D_{h}=k_{B} T / 3 \pi \eta D_{\text {dif, }}$, where $k_{B}$ is the Boltzmann's constant, $T$ is the absolute temperature, $\eta$ is the solvent viscosity and $D_{\text {dif }}$ is the measured diffusion coefficient of PGNCs. 
Thermogravimetric Analysis (TGA). TGA was performed by using a TA Instruments Q5000 system. The sample $(\sim 5 \mathrm{mg})$ was loaded into a platinum pan and was kept at $120^{\circ} \mathrm{C}$ for $30 \mathrm{~min}$ before ramping to $600{ }^{\circ} \mathrm{C}$ at a constant heating rate of $10^{\circ} \mathrm{C} /$ min under $\mathrm{N}_{2}$. Analysis was carried out using the TA Universal Analysis software package.

Electron microscopy and atomic force microscopy (AFM). Scanning electron microscopy (SEM) images were taken on a Carl Zeiss Auriga 60 FIB-SEM operated at $1.50 \mathrm{kV}$. To record crosssectional SEM images, silicon substrate coated with PGNC were cut into two halves using a diamond saw and the sample stage was tilted to 54 degrees during image acquisition. Transmission electron microscopy (TEM) images were acquired on a JEOL JEM 1400 plus microscope with a LaB6 filament operated at $120 \mathrm{kV}$. Tapping-mode AFM images were obtained from an Asylum Research MFP-3D AFM. 


\section{Calculation of solvent vapor pressures during SVA experiments.}

Conversion of volumetric flow rates to molar flow rates:

$$
\mathrm{q}_{\mathrm{N} 2}(\mathrm{~mol} / \mathrm{min})=\mathrm{Q}_{\mathrm{N} 2} \times \frac{\rho}{\mathrm{Mw}}
$$

where $\mathrm{q}_{\mathrm{N} 2}$ is the molar flow rate of $\mathrm{N}_{2}, \mathrm{Q}_{\mathrm{N} 2}$ is the volumetric flow rate of $\mathrm{N}_{2}$ in sccm, $\rho$ is the density of $\mathrm{N}_{2}$ carrier gas at $25^{\circ} \mathrm{C}$ and $\mathrm{M}_{\mathrm{w}}$ is the molecular weight of $\mathrm{N}_{2}$ carrier gas $(28 \mathrm{~g} / \mathrm{mol})$.

In an ideal gas mixture, the partial pressure of each constituent is proportional to its mole fraction. Thus, the molar flow rate of chloroform solvent vapor ( $\left.\mathrm{q}_{\mathrm{CHCl}}\right)$ can be calculated as:

$$
\frac{\mathrm{q}_{\mathrm{CHCl} 3}}{\mathrm{q}_{\mathrm{CHCl} 3}+\mathrm{q}_{\mathrm{N} 2 \text {,channel1 }}}=\frac{\mathrm{p}_{0, \mathrm{CHCl}}}{\mathrm{p}_{\text {total }}}
$$

where qN2,channel1 is the molar flow rate of $\mathrm{N}_{2}$ in Channel 1; $\mathrm{p}_{0, \mathrm{CHCl}}$ is the saturated vapor pressure of $\mathrm{CHCl}_{3}$; ptotal is the total pressure in the headspace of the liquid solvent reservoir. Considering that the SVA setup is vented to external ambient conditions, ptotal is approximated as the atmospheric pressure of $760 \mathrm{mmHg}$. From Equation (2), we can obtain

$$
\mathrm{q}_{\mathrm{CHCl} 3}=\mathrm{q}_{\mathrm{N} 2 \text {,channel1 }} \times\left[\frac{\mathrm{p}_{0, \mathrm{CHCl} 3}}{\mathrm{p}_{\text {total }}-\mathrm{p}_{0, \mathrm{CHCl} 3}}\right]
$$

The solvent vapor pressure (p) inside the SVA chamber is calculated as:

$$
\mathrm{p}=\mathrm{p}_{\text {total }} \times \frac{\mathrm{q}_{\mathrm{CHCl}}}{\mathrm{q}_{\mathrm{CHCl} 3}+\mathrm{q}_{\mathrm{N} 2 \text {, channel1 }}+\mathrm{q}_{\mathrm{N} 2 \text {,channel2 }}}
$$

where $p_{\text {total }}$ is the total pressure in the SVA chamber, which is essentially equal to $760 \mathrm{mmHg}$; $\mathrm{q}_{\mathrm{N} 2 \text {,channel2 }}$ is the molar flow rate of the diluent $\mathrm{N}_{2}$ gas in Channel 2. Combining Equations (2) and (4), we can obtain

$$
\mathrm{p}=\mathrm{p}_{0, \mathrm{CHCl} 3} \times \frac{\mathrm{q}_{\mathrm{CHCl} 3}+\mathrm{q}_{\mathrm{N} 2 \text {, channel1 }}}{\mathrm{q}_{\mathrm{CHCl} 3}+\mathrm{q}_{\mathrm{N} 2 \text {,channel1 }}+\mathrm{q}_{\mathrm{N} 2 \text {,channel2 }}}
$$

At $25^{\circ} \mathrm{C}$, the saturated vapor pressure of $\mathrm{CHCl}_{3}$ is $197 \mathrm{mmHg}^{6}$ According to Equation (3), the molar flow rate of $\mathrm{CHCl}_{3}$ exiting channel 1 is:

$$
\mathrm{q}_{\mathrm{CHCl3}}=\mathrm{q}_{\mathrm{N} 2 \text {,channel1 }}\left[\frac{197 \mathrm{mmHg}}{760 \mathrm{mmHg}-197 \mathrm{mmHg}}\right]=0.35 \mathrm{q}_{\mathrm{N} 2 \text {,channel1 }}
$$

Therefore, the $\mathrm{CHCl}_{3}$ vapor pressure inside the SVA chamber at different flow conditions can be calculated using Equations (5) and (6), and the results are provided below. 


\begin{tabular}{ccc}
\hline $\begin{array}{c}\mathbf{N}_{\mathbf{2}} \text { flow rates (sccm) } \\
\text { (Channel 1: Channel 2) }\end{array}$ & $\begin{array}{c}\text { Normalized } \mathbf{C H C l}_{\mathbf{3}} \text { vapor } \\
\text { pressure inside the SVA } \\
\text { chamber }\left(\mathbf{p} / \mathbf{p}_{\mathbf{0}}\right)\end{array}$ & $\begin{array}{c}\mathbf{C H C l}_{\mathbf{3}} \text { vapor pressure } \\
\text { inside the SVA chamber } \\
(\mathbf{m m H g})\end{array}$ \\
\hline $93: 7$ & 0.95 & 187 \\
$85: 15$ & 0.88 & 173 \\
$78: 22$ & 0.83 & 164 \\
$68: 32$ & 0.74 & 146 \\
\hline
\end{tabular}




\section{Estimation of PGNC diffusion coefficients using Phillies' model}

We use the Phillies' model $^{7}$ to establish a quantitative relationship between solvent vapor pressure and NC diffusion kinetics. The Phillies' model has been widely used to describe the selfdiffusion of macromolecules in solution over a broad range of concentrations. The dependence of diffusion coefficient (D) on polymer concentration (c) obeys the following relationship:

$$
\mathrm{D}=\mathrm{D}_{0} \mathrm{e}^{-\alpha \mathrm{c}^{v}}
$$

where $\mathrm{D}_{0}$ is the diffusion coefficient at infinite dilution, and $\alpha, v$ are system-dependent fitting parameters that are independent of $\mathrm{c}$.

Here, we use the $\alpha$ and $v$ values reported by Kohli et al. ${ }^{8}$ who studied the diffusion of nanoparticles in a polymer solution. We choose $\alpha=7.5$ and $v=0.65$ for $5.4 \mathrm{~nm}$ PGNCs, and $\alpha=$ 8.47 and $v=0.70$ for $13.5 \mathrm{~nm}$ PGNCs. $\mathrm{D}_{0}$ is determined from DLS measurements of PGNCs dissolved in $\mathrm{CHCl}_{3}$ at the concentration of $1 \mathrm{mg} / \mathrm{mL}$.

Plots of estimated diffusion coefficient of PGNCs versus PGNC volume fraction are shown in Figure S14. The diffusion coefficients are on the order of $10^{9}-10^{10} \mathrm{~cm}^{2} / \mathrm{s}$, which is in line with previous studies of nanoparticle diffusion in a concentrated polymer solution or self-diffusion of PGNCs in a concentrated solution. To put our numerical estimation of diffusion coefficients into context, we include a literature survey of nanoparticle's diffusion coefficients in concentrated solutions as well as in polymer melts (Table S2). 
Table S2. Literature survey of diffusion coefficients of nanoparticles in concentrated solutions and in polymer melts.

\begin{tabular}{|c|c|c|c|c|c|c|}
\hline $\begin{array}{l}\text { Diffusion } \\
\text { coefficient } \\
\left(\mathrm{cm}^{2} / \mathbf{s}\right) \\
\end{array}$ & Diffusant & \begin{tabular}{|l|} 
Diffusant \\
volume \\
fraction
\end{tabular} & $\begin{array}{l}\text { Polymer matrix and } \\
\text { its volume fraction }\end{array}$ & Solvent & \begin{tabular}{|l|} 
Solvent \\
volume \\
fraction
\end{tabular} & Ref. \\
\hline $10^{-9}-10^{-10}$ & $\begin{array}{l}\text { PS }(5.5,8.2 \mathrm{kDa})- \\
\text { capped } \mathrm{Fe}_{3} \mathrm{O}_{4} \mathrm{NCs} \\
(5.4,13.5 \mathrm{~nm})\end{array}$ & $0.44-0.69$ & N.A. & $\mathrm{CHCl}_{3}$ & $0.31-0.56$ & $\begin{array}{l}\text { This } \\
\text { work }\end{array}$ \\
\hline \multicolumn{7}{|c|}{$\begin{array}{l}\text { Nanoparticle diffusion in a concentrated polymer solution or self-diffusion of PGNCs in a } \\
\text { concentrated solution }\end{array}$} \\
\hline $10^{-6}-10^{-10}$ & $\begin{array}{l}\text { citrate-capped Au } \\
\text { NCs }(5-20 \mathrm{~nm})\end{array}$ & $10^{-9}$ & $\begin{array}{l}5 \mathrm{kDa} \text { and } 35 \mathrm{kDa} \\
\mathrm{PEO}, \Phi_{\mathrm{pol}}: 0-0.4\end{array}$ & $\mathrm{H}_{2} \mathrm{O}$ & $\sim 0.6-1.0$ & 8 \\
\hline $10^{-6}-10^{-10}$ & $\begin{array}{c}\text { oleylamine-capped } \\
\text { Au and oleic-acid- } \\
\text { capped } \mathrm{Fe}_{2} \mathrm{O}_{3} \mathrm{NCs} \\
(3-12 \mathrm{~nm})\end{array}$ & 0.09 & $\begin{array}{c}\text { PS (40 kDa)-b-P4VP } \\
(5.6 \mathrm{kDa})(\mathrm{PDP}) 1 \\
\Phi_{\text {pol: }} 0.41-0.81\end{array}$ & $\mathrm{CHCl}_{3}$ & $0.1-0.5$ & 9 \\
\hline $10^{-8}-10^{-11}$ & $\begin{array}{c}\text { PS-capped (15.6, } \\
80.4 \mathrm{kDa}) \mathrm{SiO}_{2} \\
\text { nanoparticles }(20 \\
\mathrm{nm})\end{array}$ & $10^{-4}-0.6$ & N.A. & $\mathrm{CCl}_{4}$ & $\sim 0.4-1.0$ & 10 \\
\hline \multicolumn{7}{|c|}{ Nanoparticle or PGNC diffusion in a polymer melt } \\
\hline $\begin{array}{c}\text { Diffusion } \\
\text { coefficient } \\
\left(\mathrm{cm}^{2} / \mathrm{s}\right)\end{array}$ & Diffusant & \begin{tabular}{|c|} 
Diffusant \\
volume \\
fraction
\end{tabular} & \multicolumn{3}{|c|}{ Polymer matrix and its volume fraction } & Ref. \\
\hline $10^{-13}-10^{-15}$ & $\begin{array}{c}\text { PMMA }(16,21 \\
\text { kDa)-capped Fe } \mathrm{O}_{4} \\
\text { NCs }(4.3 \mathrm{~nm})\end{array}$ & $0.40-0.50$ & \multicolumn{3}{|c|}{ 4-52 kDa PMMA, $\Phi_{\mathrm{pol}}: 0.50-0.60$} & 11 \\
\hline $10^{-13}-10^{-14}$ & $\begin{array}{l}\text { citrate-capped Au } \\
\text { NCs }(5-20 \mathrm{~nm})\end{array}$ & $\sim 10^{-9}$ & \multicolumn{3}{|c|}{$\begin{array}{l}180 \mathrm{kDa} \text { PBMA, } \\
\Phi_{\text {pol: }} \sim 1.0\end{array}$} & 12 \\
\hline $10^{-14}-10^{-16}$ & $\begin{array}{l}\text { oleic-acid-capped } \\
\text { CdSe NCs }(4.4 \mathrm{~nm})\end{array}$ & 0.08 & \multicolumn{3}{|c|}{$\begin{array}{l}393 \mathrm{kDa} P S, \\
\Phi_{\text {pol: }} 0.92\end{array}$} & 13 \\
\hline
\end{tabular}




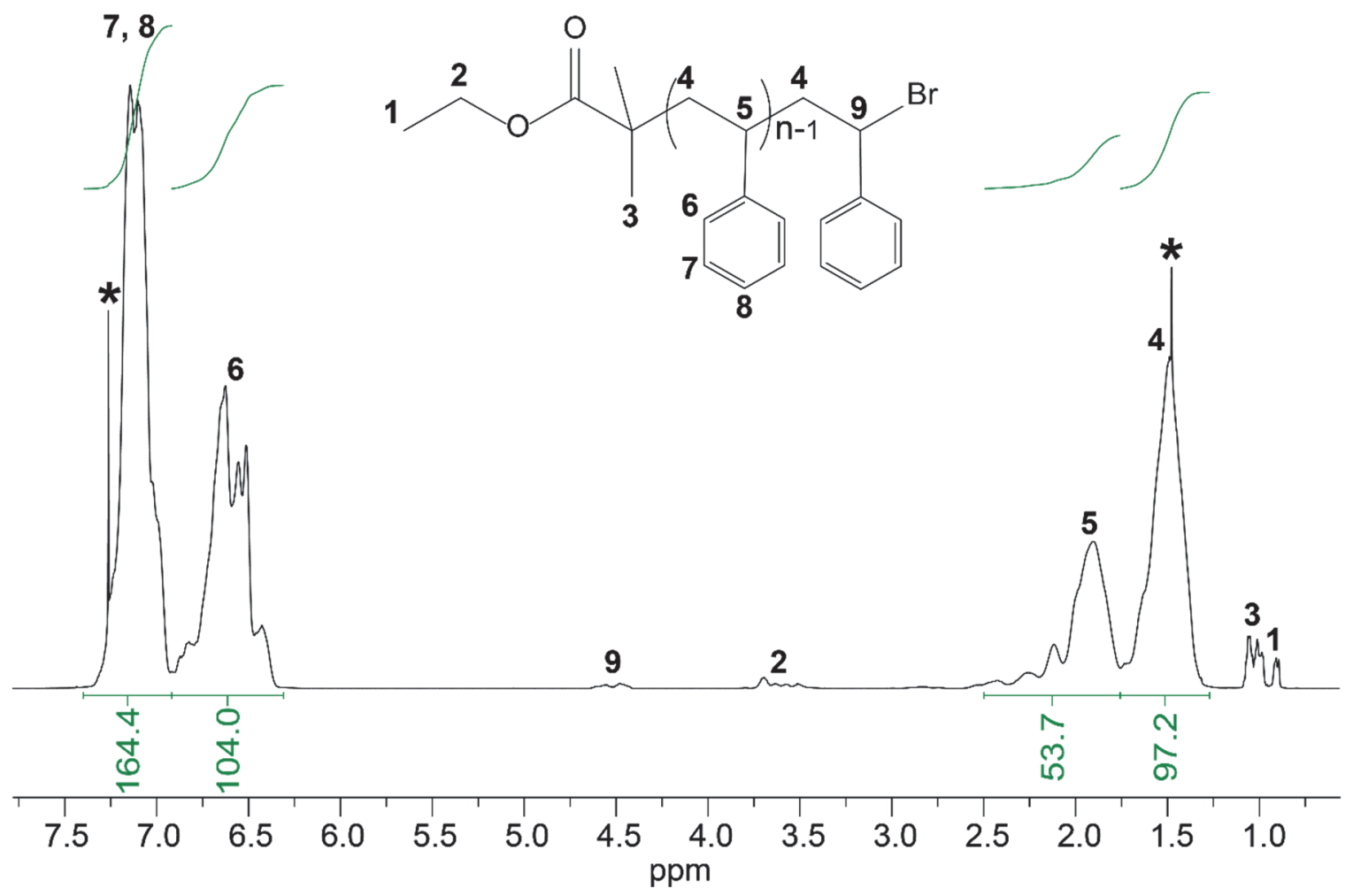

Figure S1. Representative ${ }^{1} \mathrm{H}$ NMR spectrum of as-synthesized PS-Br in $\mathrm{CDCl}_{3}$. The asterisks denote residual solvent peaks. 

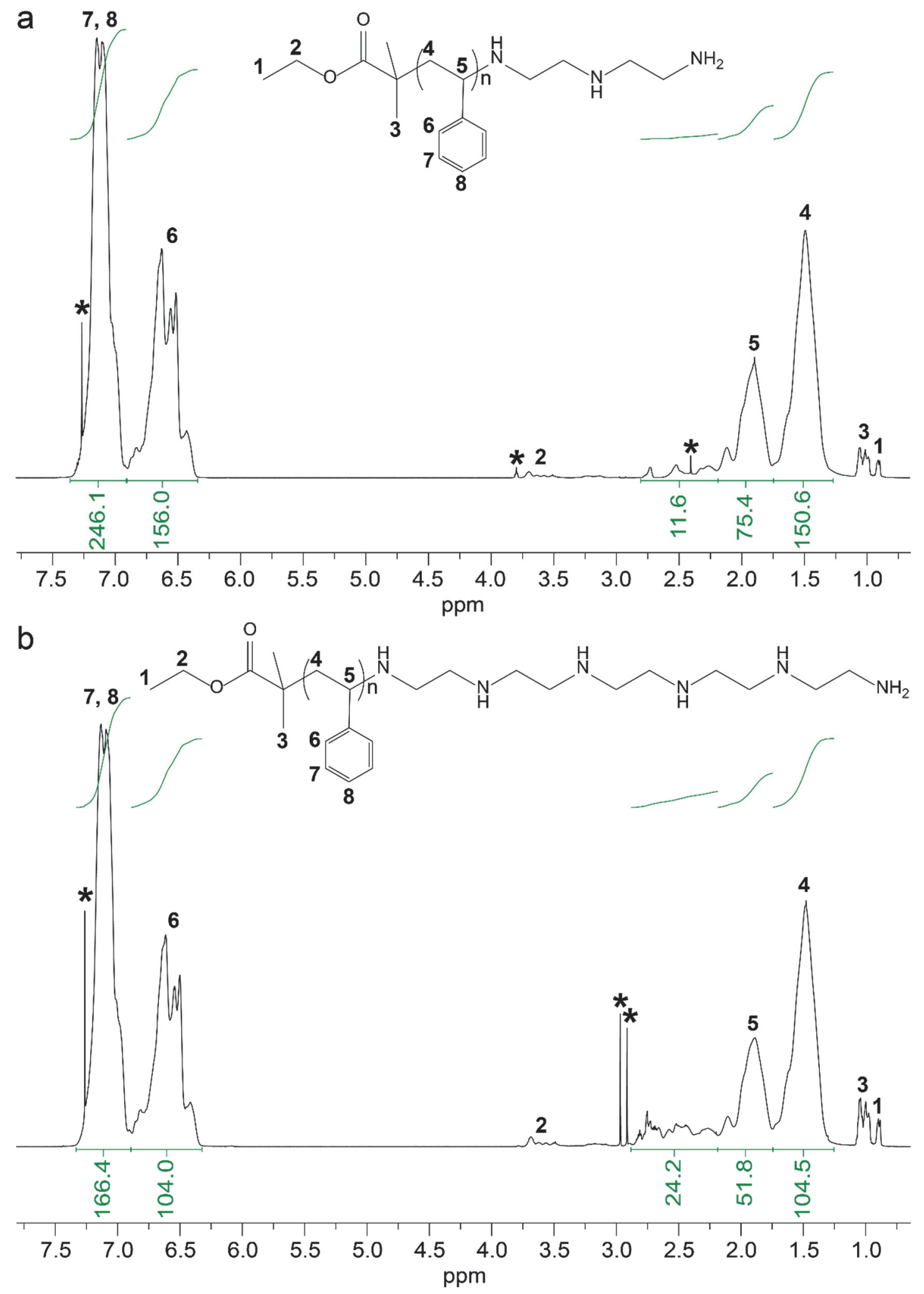

Figure S2. Representative ${ }^{1} \mathrm{H}$ NMR spectra of as-synthesized (a) PS-DETA and (b) PS-PEHA in $\mathrm{CDCl}_{3}$. The asterisks denote residual solvent peaks. 

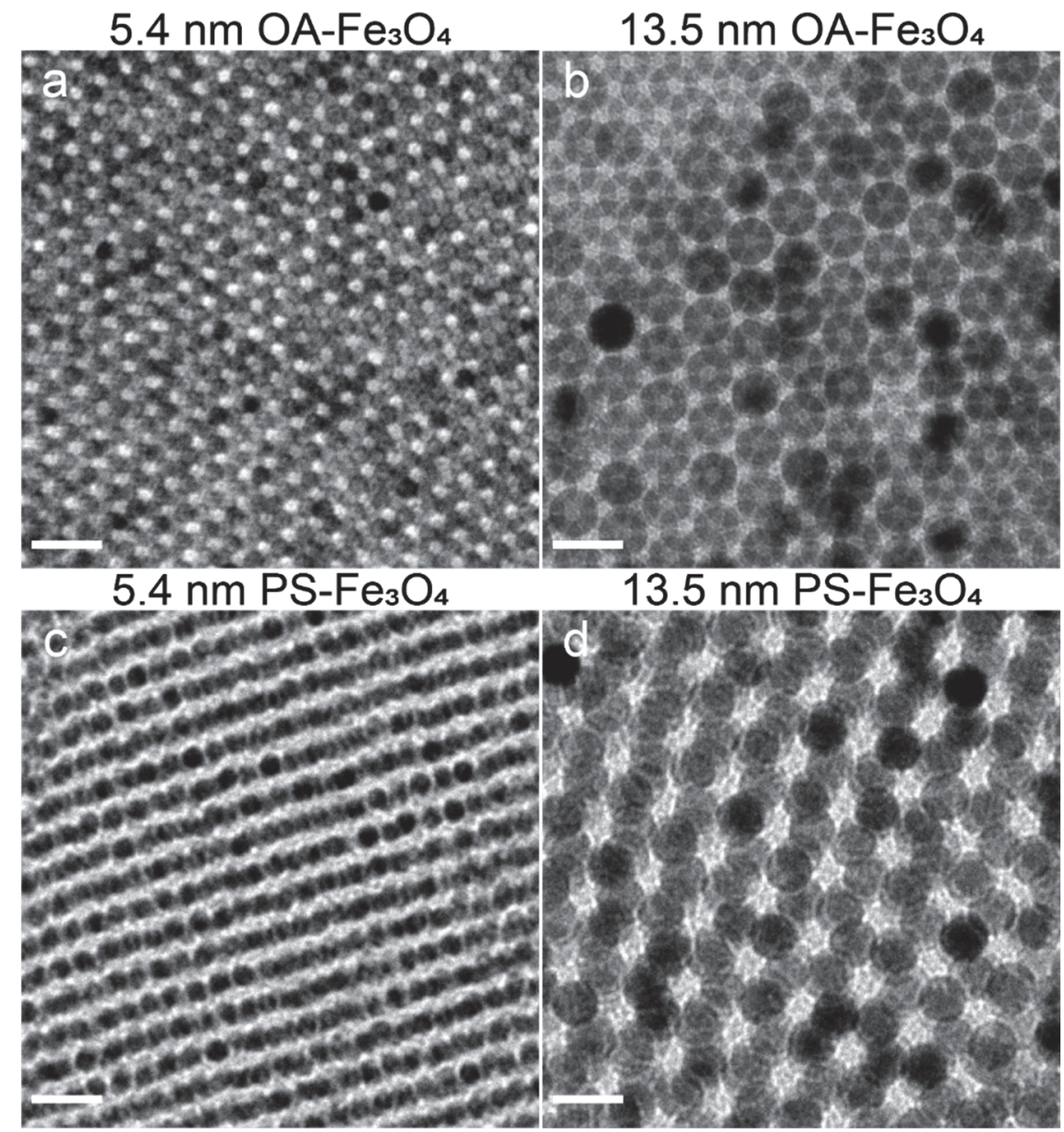

Figure S3. (a, b) TEM images of oleate-capped (a) $5.4 \mathrm{~nm}$ (core diameter) and (b) $13.5 \mathrm{~nm}$ (core diameter) $\mathrm{Fe}_{3} \mathrm{O}_{4}$ NCs. (c, d) TEM images of (c) $5.4 \mathrm{~nm}$ and (d) $13.5 \mathrm{~nm} \mathrm{Fe} \mathrm{O}_{4}$ NCs grafted with (c) $5.5 \mathrm{kDa}$ PS-PEHA and (d) $8.2 \mathrm{kDa}$ PS-DETA. Scale bars: $20 \mathrm{~nm}$. 

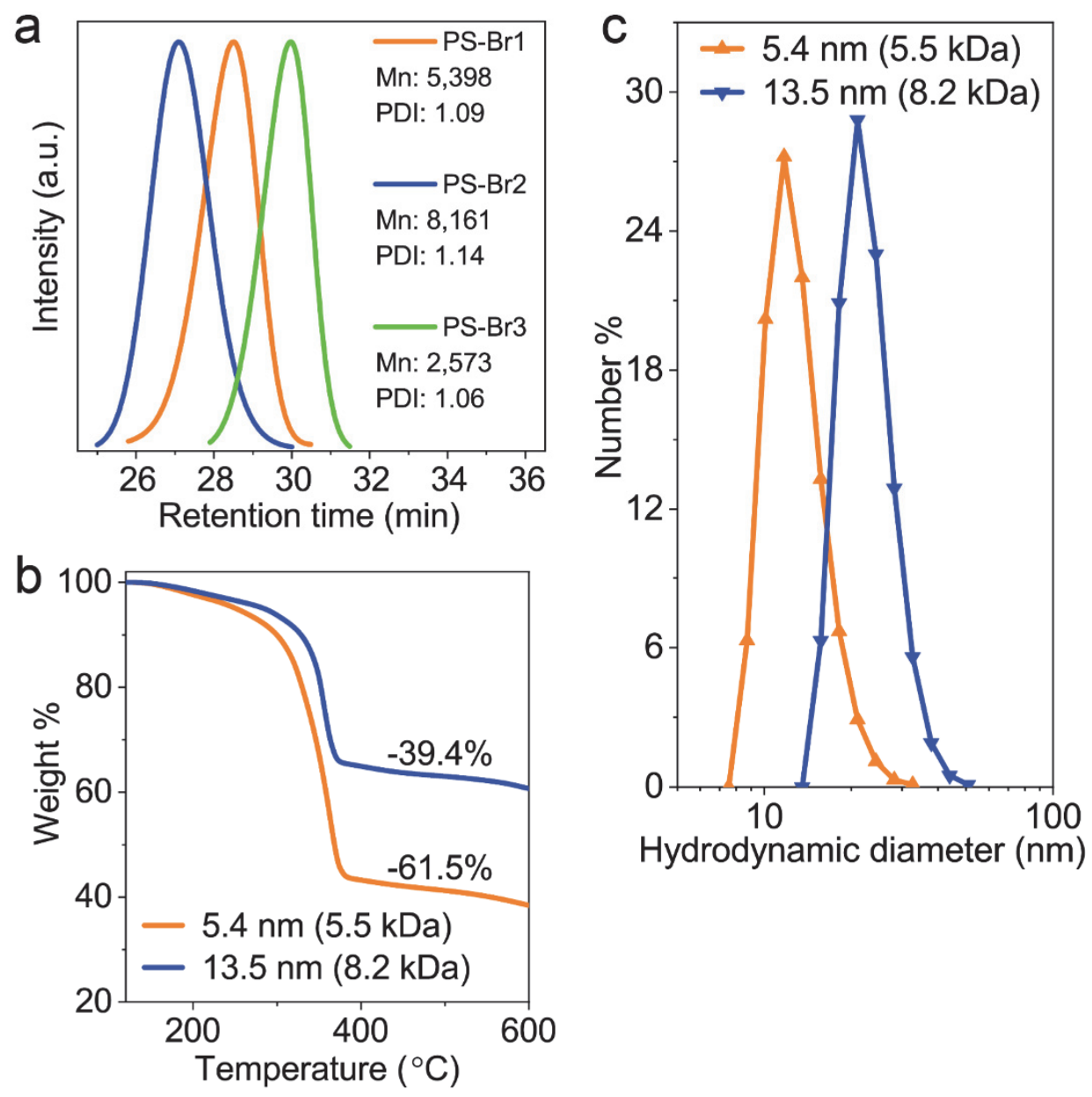

Figure S4. (a) Normalized GPC traces of PS-Br samples. The number-averaged molecular weight $\left(\mathrm{M}_{\mathrm{n}}\right)$ and polydispersity index (PDI) are indicated on the plot. (b) TGA characterization results of PS-capped $\mathrm{Fe}_{3} \mathrm{O}_{4}$ NCs. The weight loss is indicated for each trace on the graph. (c) Numberaveraged hydrodynamic diameters of PS-capped $\mathrm{Fe}_{3} \mathrm{O}_{4} \mathrm{NCs}$ dispersed in $\mathrm{CHCl}_{3}$ determined from DLS measurements. 
Table S3. Detailed characterization of the PGNC combination discussed in the main text. Core sizes of $\mathrm{Fe}_{3} \mathrm{O}_{4} \mathrm{NCs}$, characteristics of polystyrene ligands, grafting densities of polystyrene and effective sizes of PGNCs in the solid and solvated states.

\begin{tabular}{|c|c|c|}
\hline & 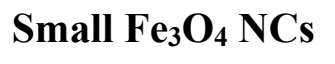 & Large $\mathrm{Fe}_{3} \mathrm{O}_{4} \mathrm{NCs}$ \\
\hline Core diameter of $\mathrm{Fe}_{3} \mathrm{O}_{4} \mathrm{NCs}(\mathrm{nm})$ & 5.4 & 13.5 \\
\hline Polymer ligands & PS-PEHA & PS-DETA \\
\hline$M_{n}$ of PS ligands (kDa) & 5.5 & 8.2 \\
\hline PDI of PS ligands & 1.09 & 1.14 \\
\hline Grafting density of PGNCs (chains/nm²) & 0.81 & 0.56 \\
\hline $\begin{array}{l}\text { Effective diameter of PGNCs in the solid state } \\
\qquad(\mathrm{nm})\end{array}$ & 12.0 & 19.8 \\
\hline Hydrodynamic diameter of PGNCs (nm) & 13.0 & 22.9 \\
\hline
\end{tabular}

Note: 1. The $\mathrm{M}_{\mathrm{n}}$ of PS-PEHA and PS-DETA were estimated from GPC data of PS-Br. Specifically, $\mathrm{M}_{\mathrm{n}}(\mathrm{PS}-\mathrm{PEHA})=\mathrm{M}_{\mathrm{n}}(\mathrm{PS}-\mathrm{Br})+\mathrm{M}_{\mathrm{n}}(\mathrm{PEHA})-\mathrm{M}_{\mathrm{n}}(\mathrm{HBr}) ; \mathrm{M}_{\mathrm{n}}(\mathrm{PS}-\mathrm{DETA})=\mathrm{M}_{\mathrm{n}}(\mathrm{PS}-\mathrm{Br})+$ $\mathrm{Mn}_{\mathrm{n}}(\mathrm{DETA})-\mathrm{Mn}_{\mathrm{n}}(\mathrm{HBr})$.

2. Grafting densities of PS on PGNCs were estimated from the TGA data.

3. The effective diameters of PGNCs in the solid state refer to the average nearest-neighbor center-to-center interparticle distances measured from multiple TEM images of twodimensional hexagonal PGNC superlattices. 


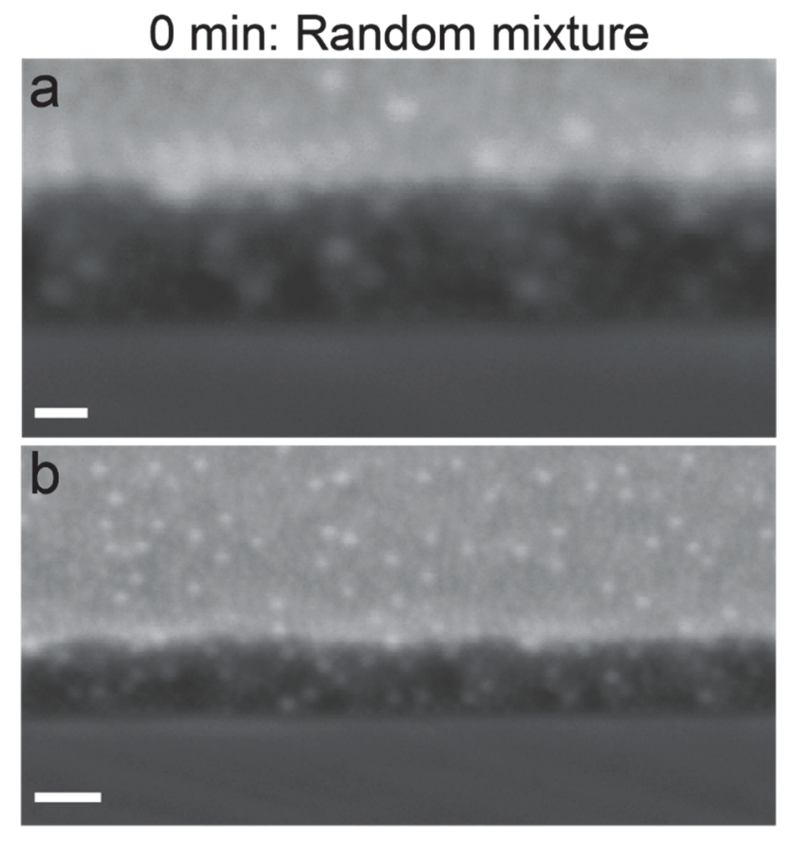

3 min: Initial nucleation

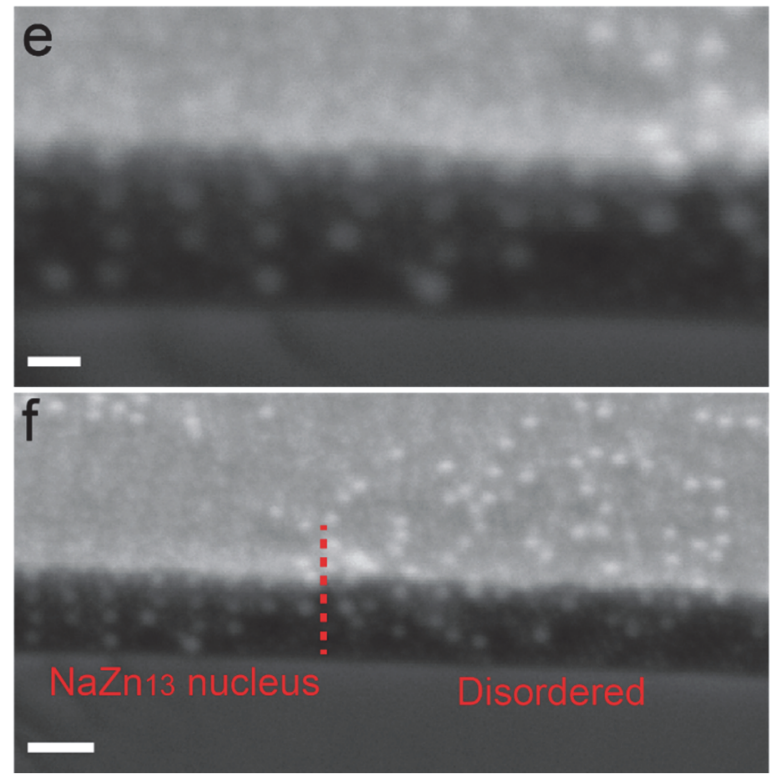

Figure S5. Structure evolution of spin-coated binary PGNC thin films upon solvent annealing under $0.95 \mathrm{p} / \mathrm{p}_{0}$ of $\mathrm{CHCl}_{3}$ vapor. Representative (a, c, e, g) high-magnification and (b, d, f, h) lowmagnification cross-sectional SEM images of PGNC films $(a, b)$ before and after SVA for (c, d) 2 min, (e, f) 3 min and (g, h) 15 min are shown. Scale bars: (a, c, e, g) $20 \mathrm{~nm},(\mathrm{~b}, \mathrm{~d}, \mathrm{f}, \mathrm{h}) 50 \mathrm{~nm}$. 

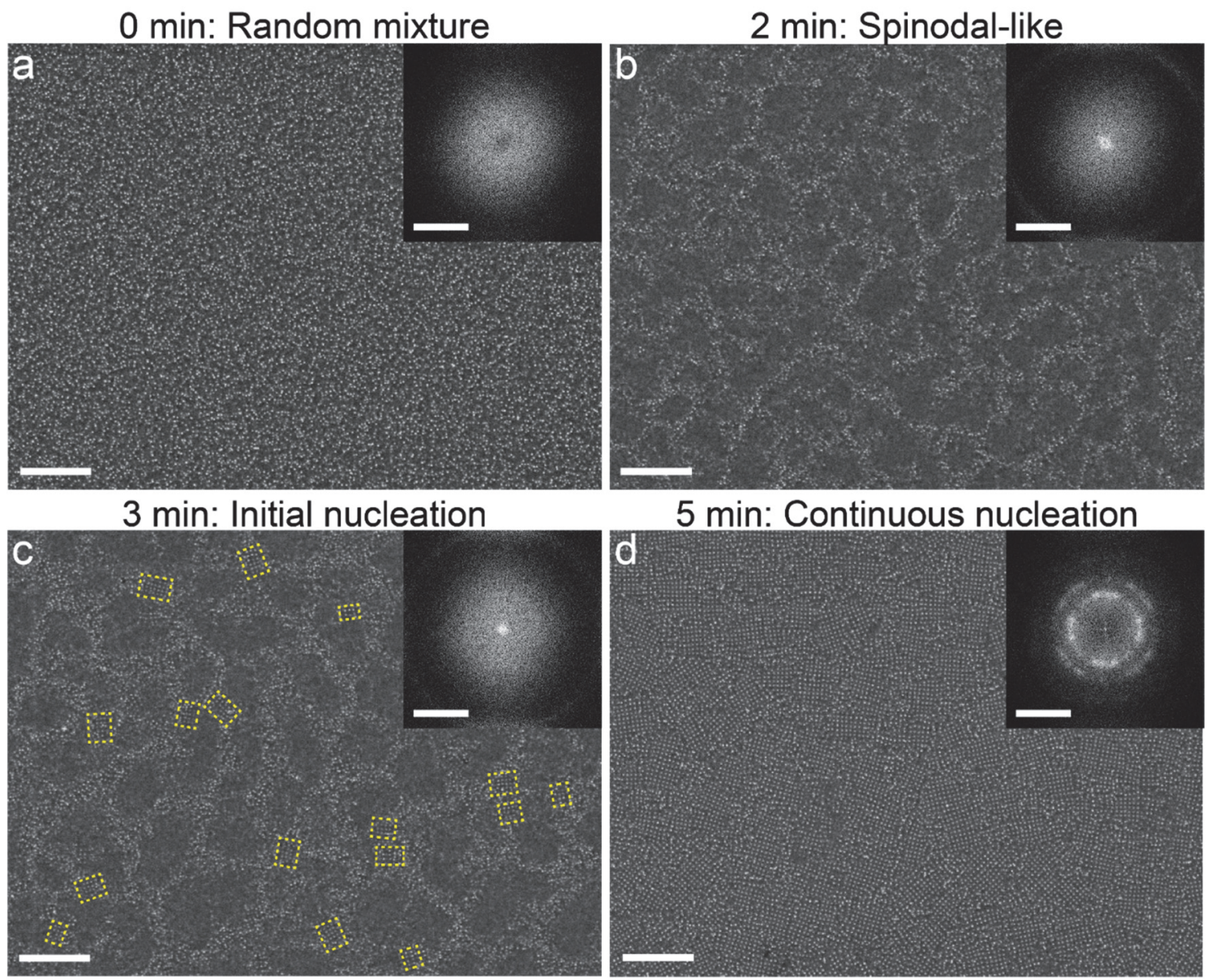

5 min: Continuous nucleation

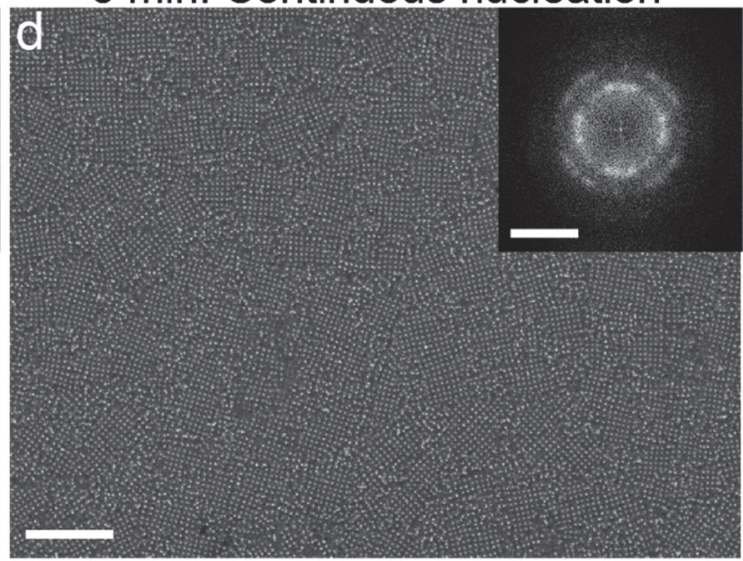

10 min: Ripening

15 min: Extended $\mathrm{NaZn}_{13}$
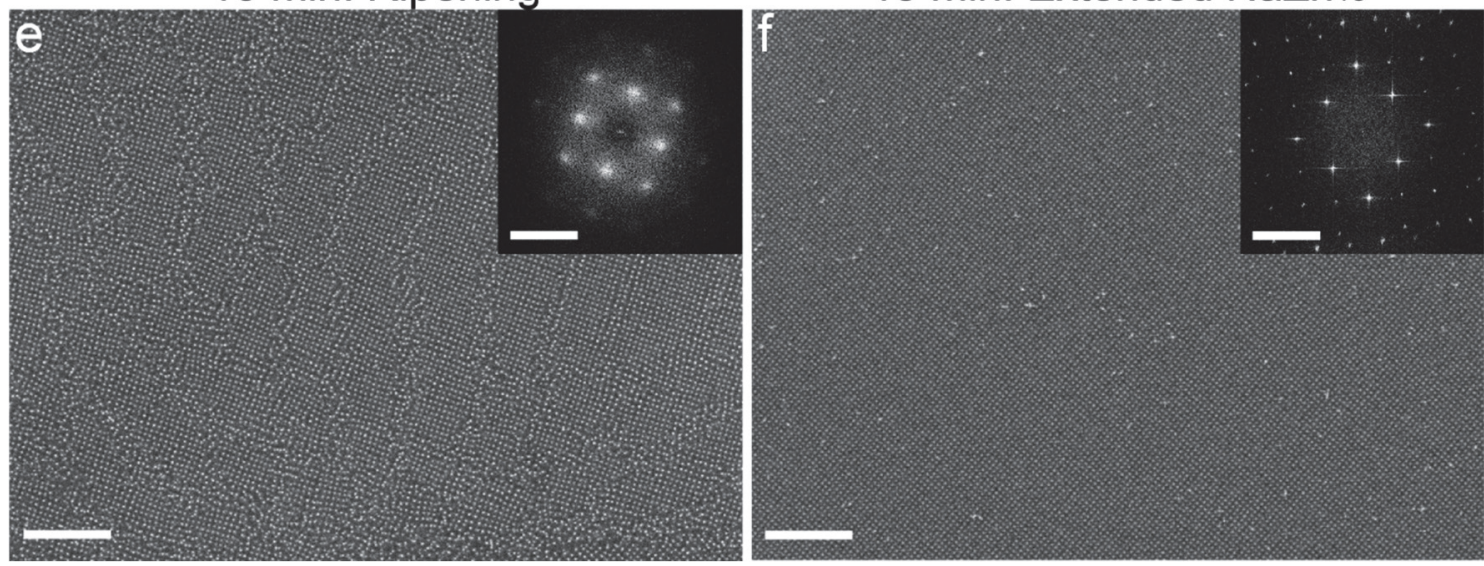

Figure S6. Structure evolution of spin-coated binary PGNC thin films upon solvent annealing under $0.95 \mathrm{p} / \mathrm{p}_{0}$ of $\mathrm{CHCl}_{3}$ vapor. Representative low-magnification SEM images and corresponding fast Fourier transform (FFT) patterns (top insets) of PGNC films (a) before and after SVA for (b) $2 \mathrm{~min}$, (c) $3 \mathrm{~min}$, (d) $5 \mathrm{~min}$, (e) $10 \mathrm{~min}$ and (f) $15 \mathrm{~min}$ are shown. Scale bars: (main SEM images) $500 \mathrm{~nm}$, (FFT patterns) $0.05 \mathrm{~nm}^{-1}$. 

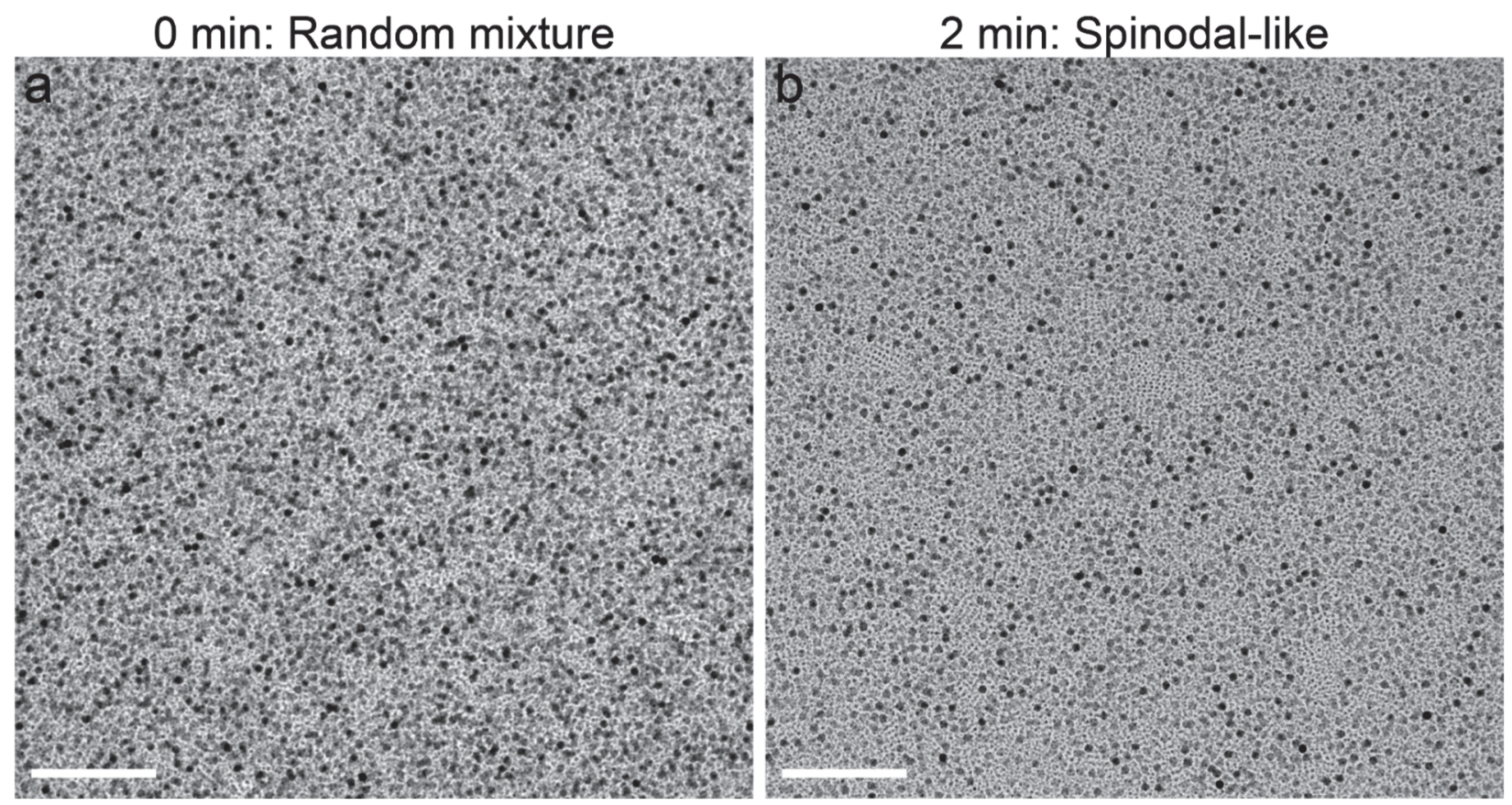

Figure S7. Representative TEM images of PGNC films (a) before and after SVA for (b) $2 \mathrm{~min}$ under $0.95 \mathrm{p} / \mathrm{p}_{0}$ of $\mathrm{CHCl}_{3}$ vapor. Scale bars: $200 \mathrm{~nm}$. 

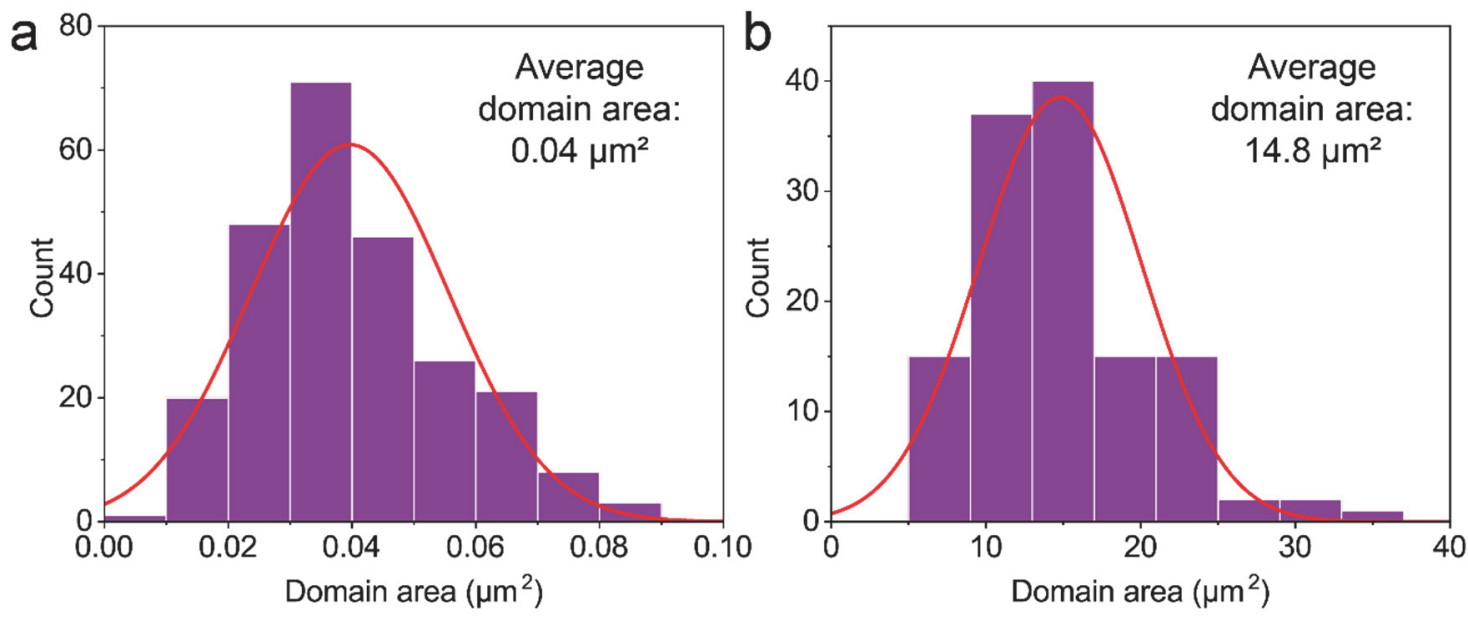

Figure S8. Histograms of $\mathrm{NaZn}_{13}$-type superstructure domain areas at the stage of (a) continuous nucleation and (b) extended NaZn 13 after SVA for (a) 5 min and (b) 15 min under 0.95 p/po of $\mathrm{CHCl}_{3}$ vapor. The red curve represents Gaussian fit to the corresponding distribution histogram. 


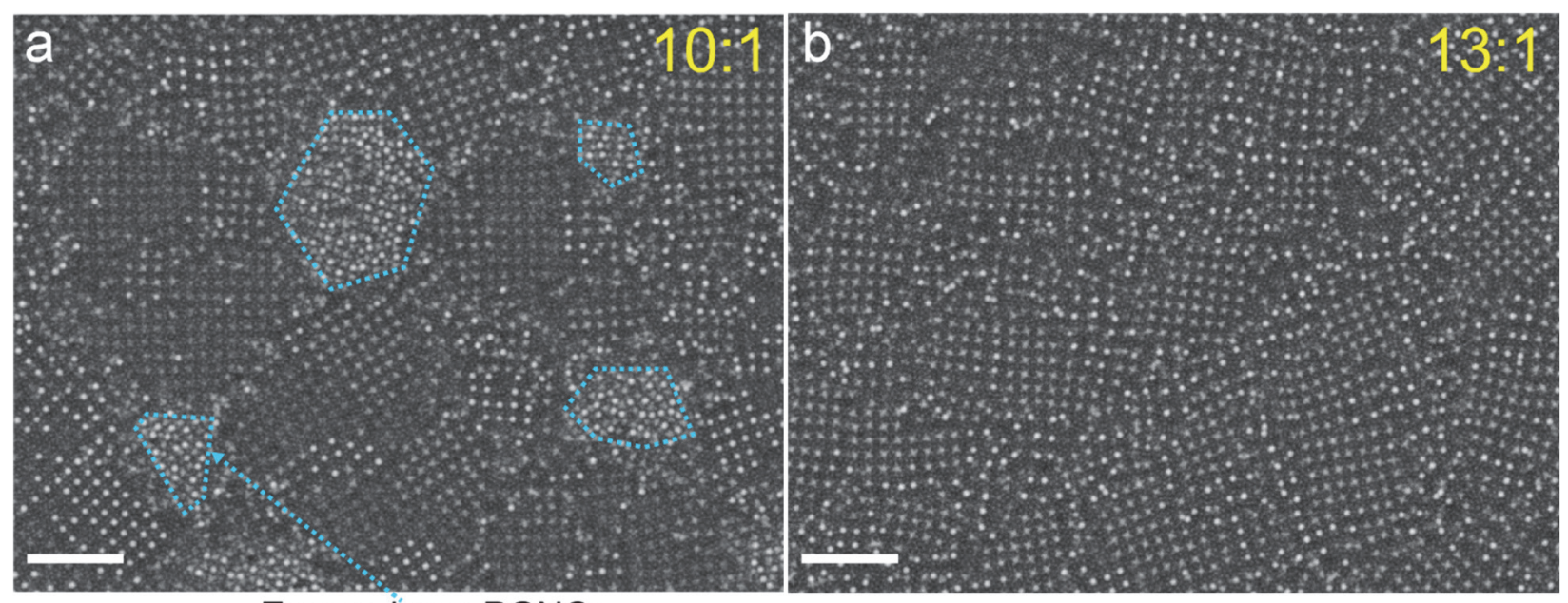

Excess large PGNCs

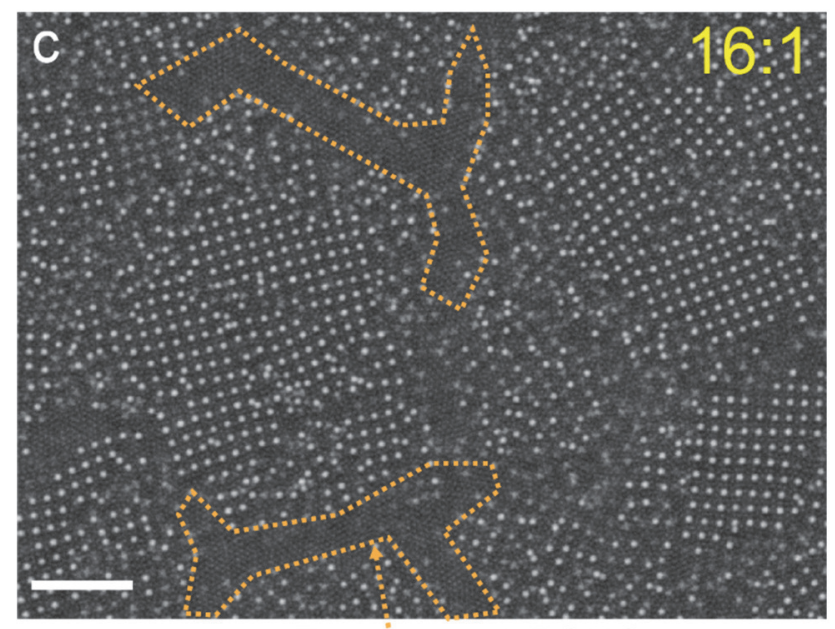

Excess small PGNCs

Figure S9. SEM images showing the effect of off-stoichiometry on the morphology of solventannealed PGNC thin films with the number ratios of (a) 10:1, (b) 13:1 and (c) 16:1 between small and large PGNCs. All films were solvent annealed under $0.95 \mathrm{p} / \mathrm{p}_{0}$ of $\mathrm{CHCl}_{3}$ vapor for $5 \mathrm{~min}$. Scale bars: $200 \mathrm{~nm}$. 

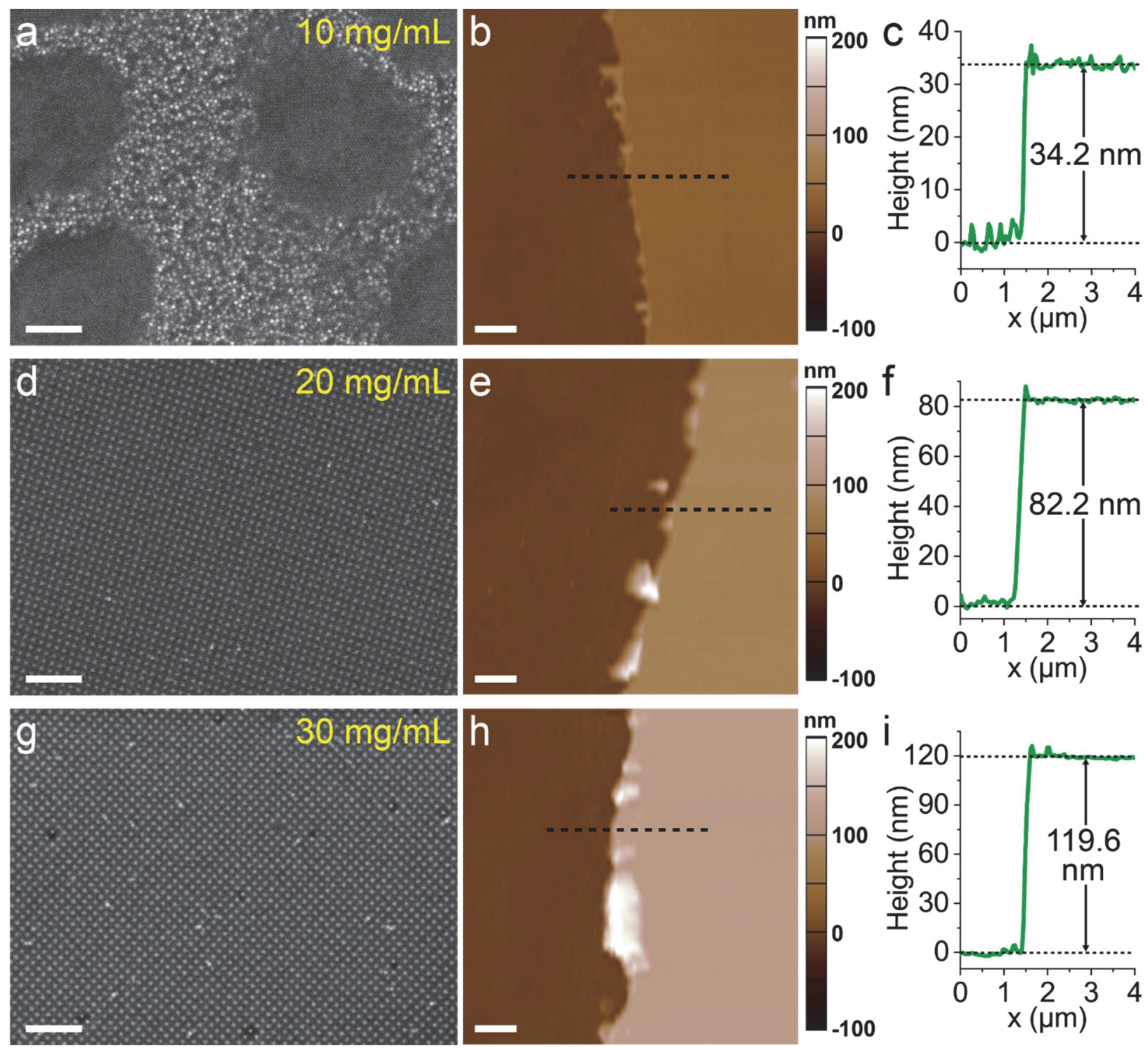

Figure S10. Effect of total PGNC concentration on the morphology of solvent-annealed PGNC thin films spin-coated from a toluene solution of (a-c) $10 \mathrm{mg} / \mathrm{mL}$, (d-f) $20 \mathrm{mg} / \mathrm{mL}$, (g-i) $30 \mathrm{mg} / \mathrm{mL}$ PGNCs followed by SVA under $0.95 \mathrm{p} / \mathrm{p}_{0}$ of $\mathrm{CHCl}_{3}$ vapor. Representative SEM images (a, d, g) of solvent-annealed PGNC films, AFM images (b, e, h) and height profiles (c, f, i) of as-spun PGNC films are shown. Scale bars: (a, d, g) $200 \mathrm{~nm},(\mathrm{~b}, \mathrm{e}, \mathrm{h}) 1 \mu \mathrm{m}$. 

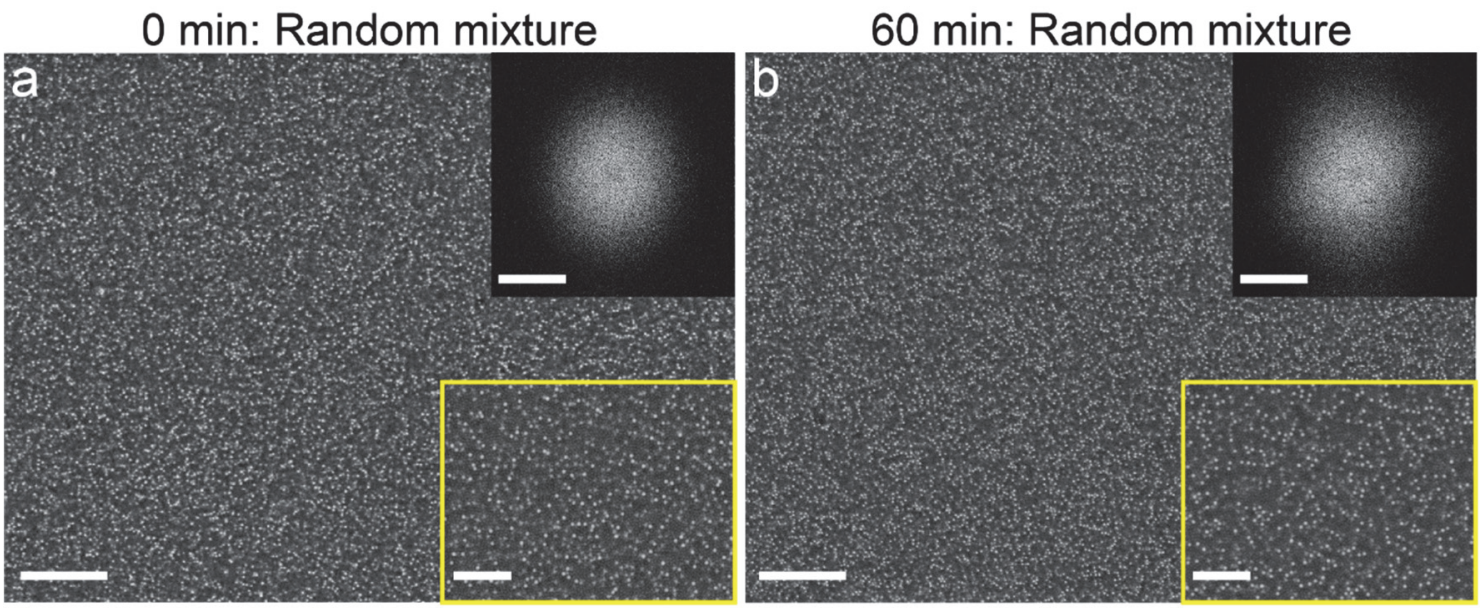

120 min: Random mixture

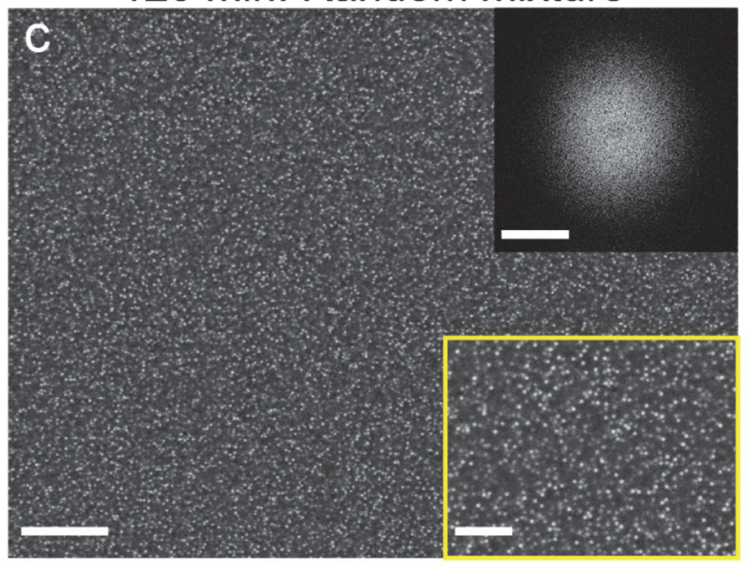

180 min: Random mixture

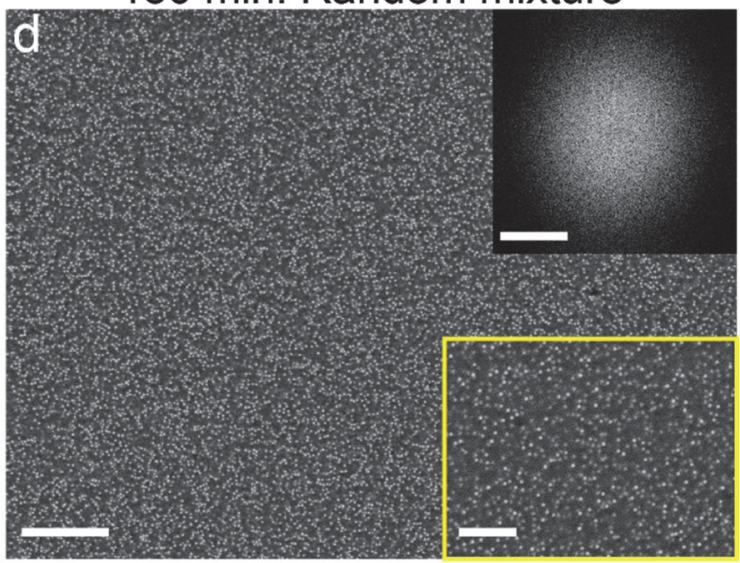

300 min: Random mixture

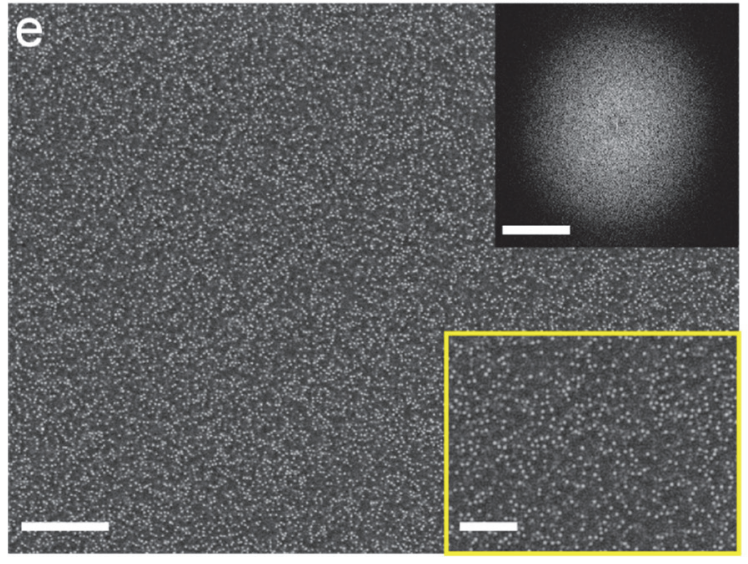

Figure S11. Structure evolution of spin-coated binary PGNC films upon solvent annealing under $0.74 \mathrm{p} / \mathrm{p}_{0}$ of $\mathrm{CHCl}_{3}$ vapor. Representative low-magnification SEM images, high-magnification SEM images (bottom insets) and corresponding FFT patterns (top insets) of PGNC films (a) before and after SVA for (b) $60 \mathrm{~min}$, (c) $120 \mathrm{~min}$, (d) $180 \mathrm{~min}$, and (e) $300 \mathrm{~min}$ are shown. Scale bars: (main SEM images) $500 \mathrm{~nm}$, (bottom insets) $200 \mathrm{~nm}$, (FFT patterns) $0.05 \mathrm{~nm}^{-1}$. 

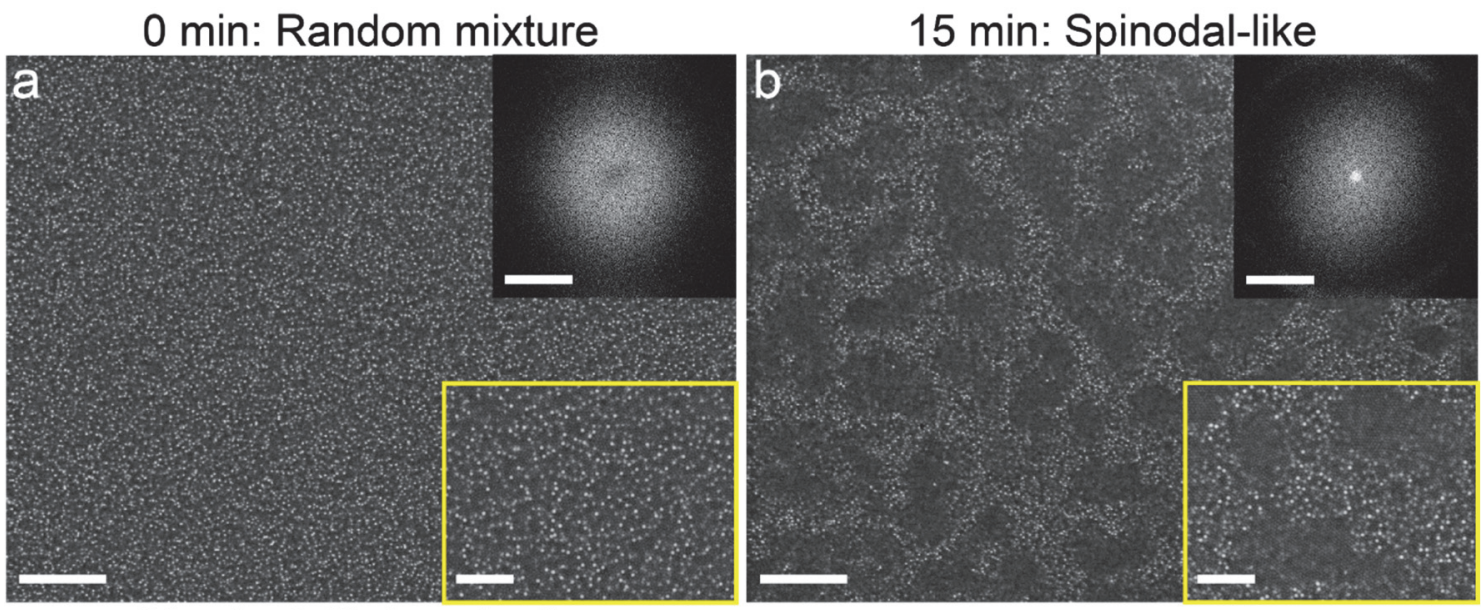

\section{0 min: Initial nucleation}

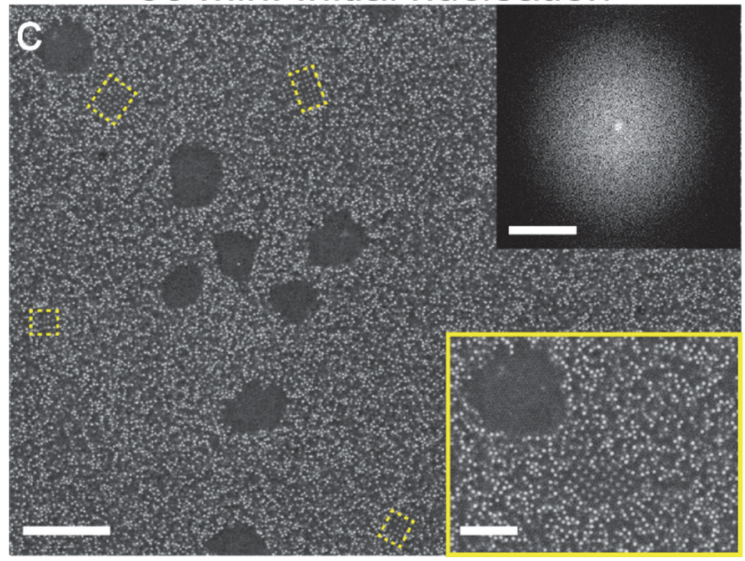

Figure S12. Structure evolution of spin-coated binary PGNC thin films upon solvent annealing under $0.83 \mathrm{p} / \mathrm{p}_{0}$ of $\mathrm{CHCl}_{3}$ vapor. Representative low-magnification SEM images, highmagnification SEM images (bottom insets) and corresponding FFT patterns (top insets) of PGNC films (a) before and after SVA for (b) 15 min, and (c) 90 min are shown. Scale bars: (main SEM images) $500 \mathrm{~nm}$, (bottom insets) $200 \mathrm{~nm}$, (FFT patterns) $0.05 \mathrm{~nm}^{-1}$. 

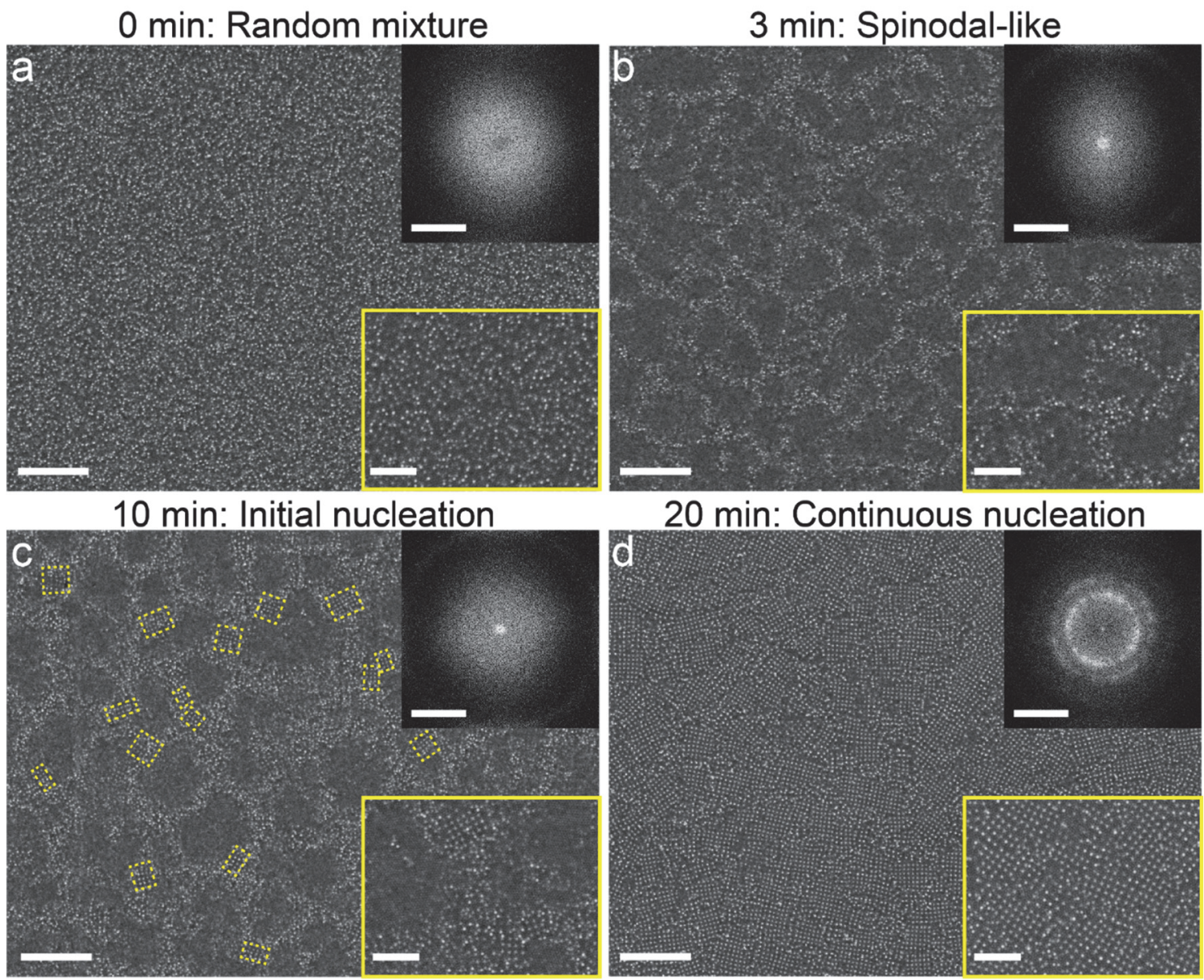

20 min: Continuous nucleation

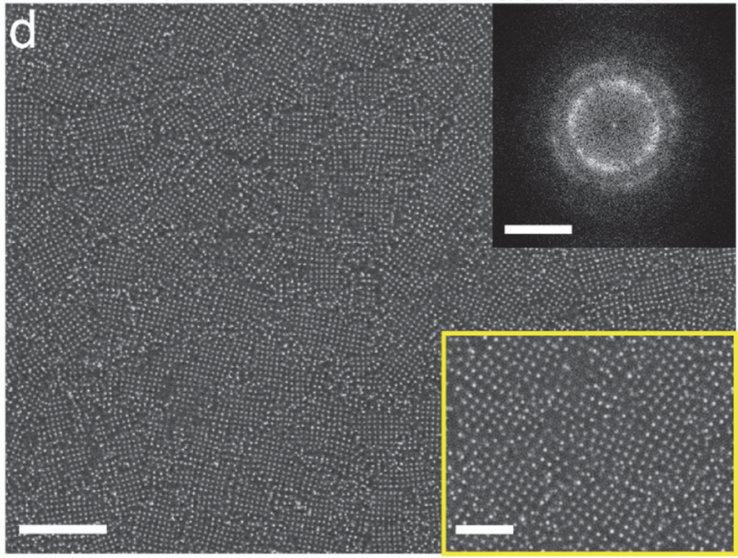

30 min: Ripening

40 min: Extended $\mathrm{NaZn}_{13}$
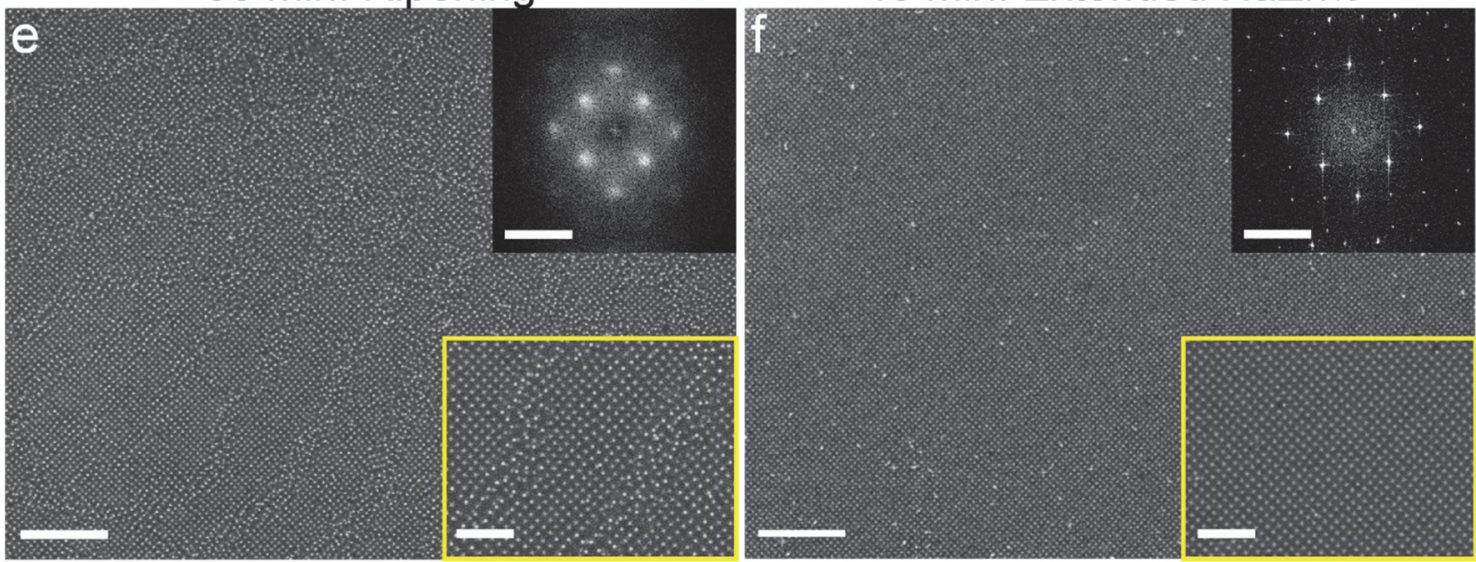

Figure S13. Structure evolution of spin-coated binary PGNC thin films upon solvent annealing under $0.88 \mathrm{p} / \mathrm{p}_{0}$ of $\mathrm{CHCl}_{3}$ vapor. Representative low-magnification SEM images, highmagnification SEM images (bottom insets) and corresponding FFT patterns (top insets) of PGNC films (a) before and after SVA for (b) $3 \mathrm{~min}$, (c) $10 \mathrm{~min}$, (d) $20 \mathrm{~min}$, (e) $30 \mathrm{~min}$ and (f) $40 \mathrm{~min}$ are shown. Scale bars: (main SEM images) $500 \mathrm{~nm}$, (bottom insets) $200 \mathrm{~nm}$, (FFT patterns) 0.05 $\mathrm{nm}^{-1}$. 


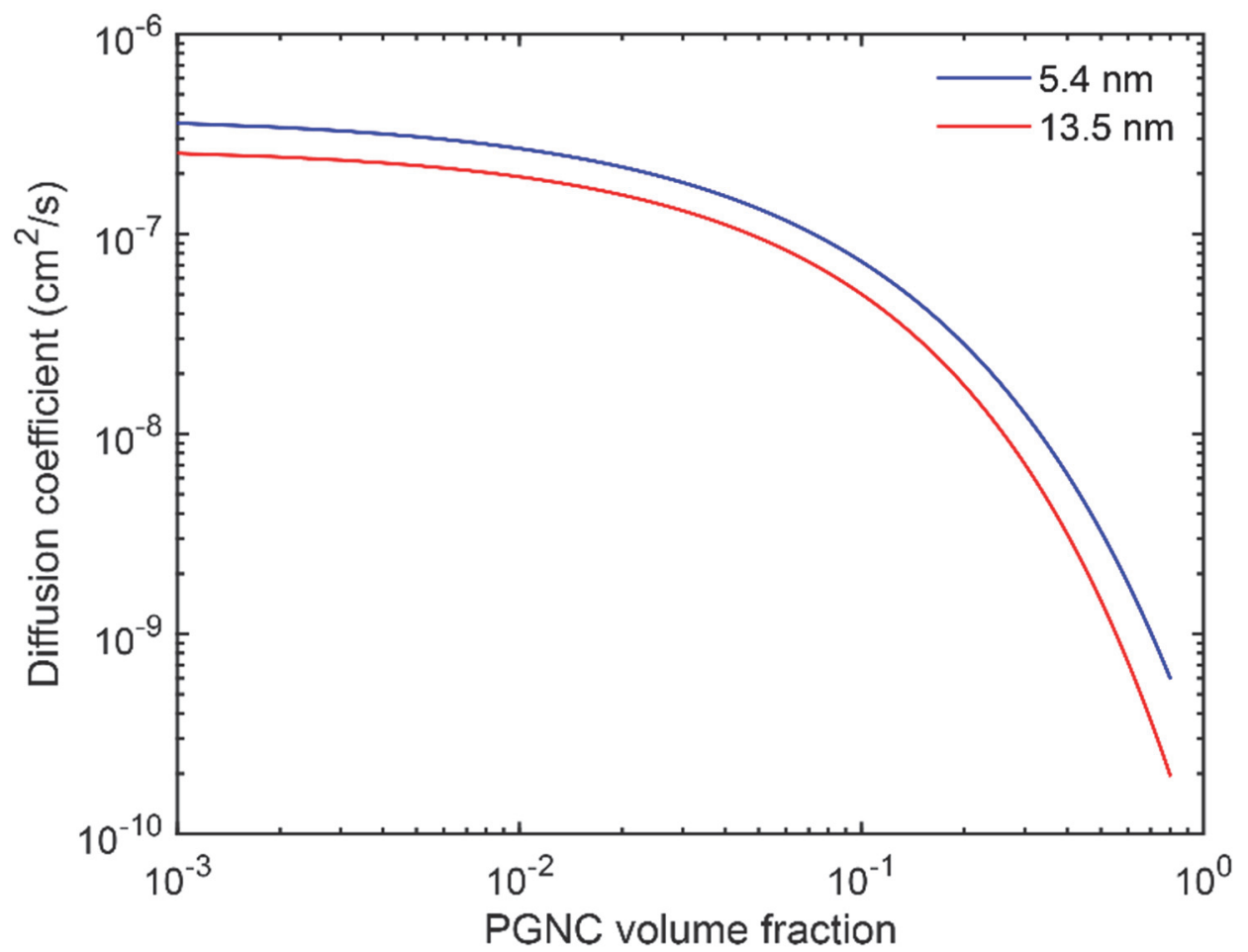

Figure S14. Estimated diffusion coefficients of PGNC as a function of PGNC volume fraction using Phillies' model. 


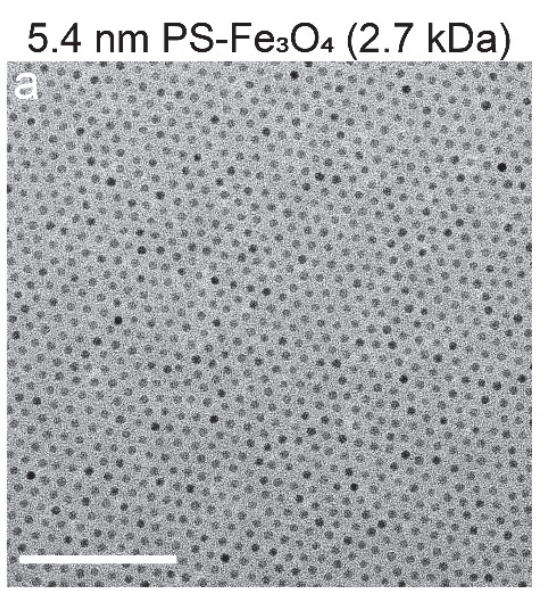

0 min: Random mixture

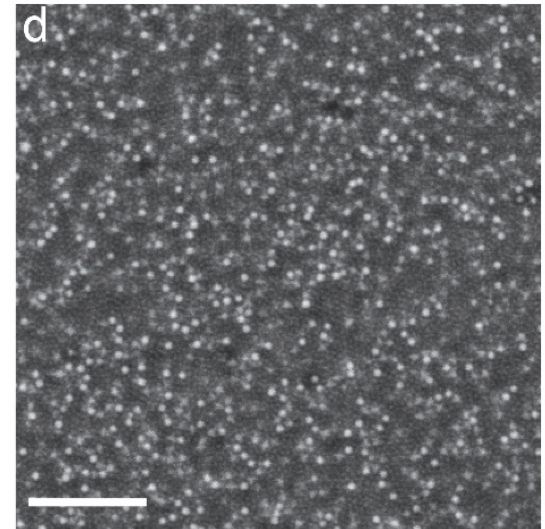

$10 \mathrm{~min}$ : Continuous nucleation

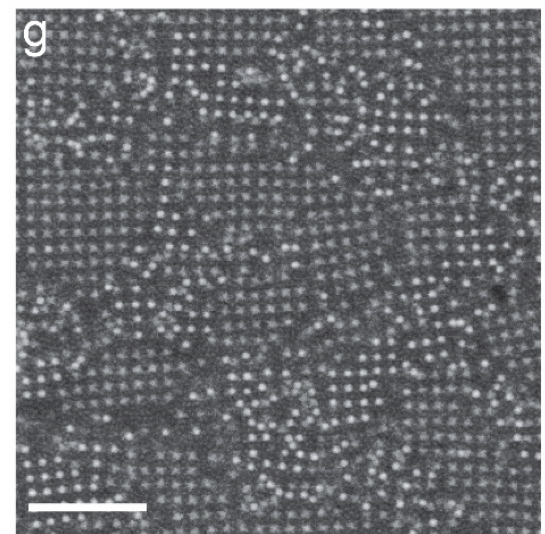

$13.5 \mathrm{~nm} \mathrm{PS}-\mathrm{Fe}_{3} \mathrm{O}_{4}(2.7 \mathrm{kDa})$

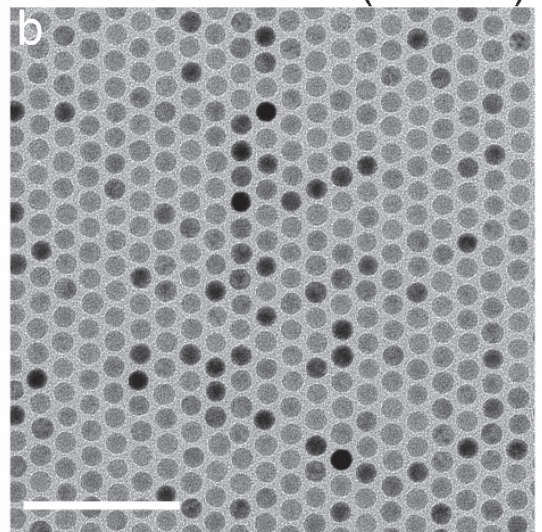

2 min: Spinodal-like

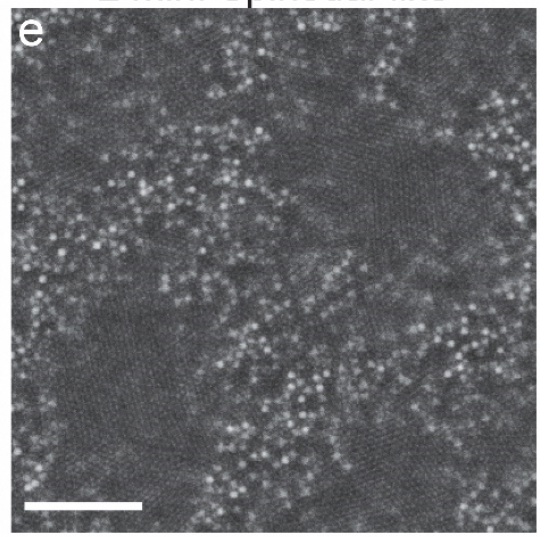

15 min: Ripening

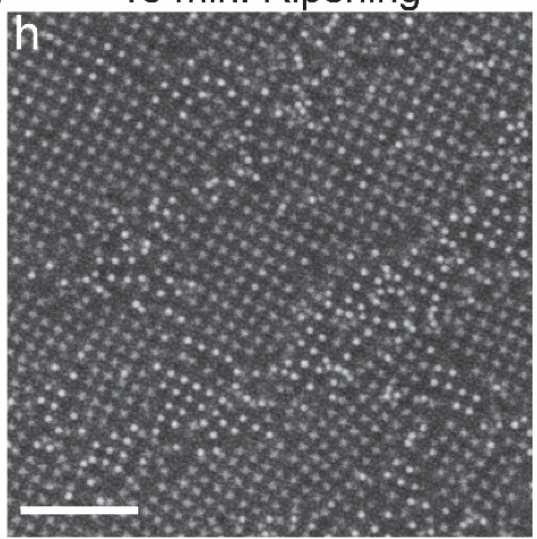

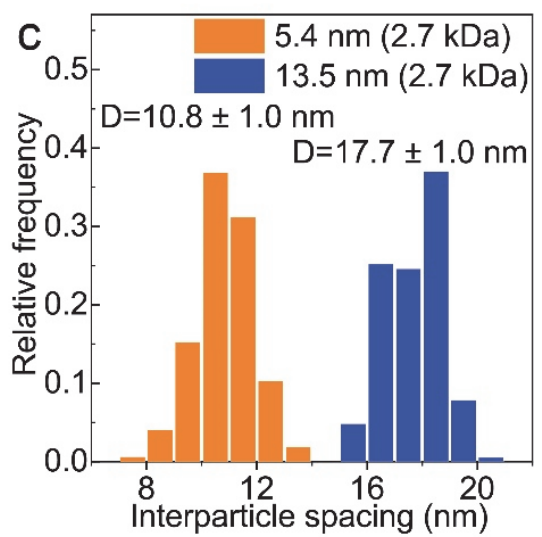

5 min: Initial nucleation

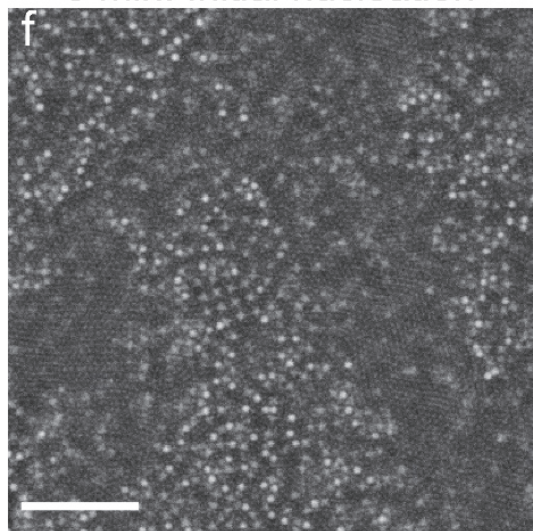

25 min: Extended NaZn13

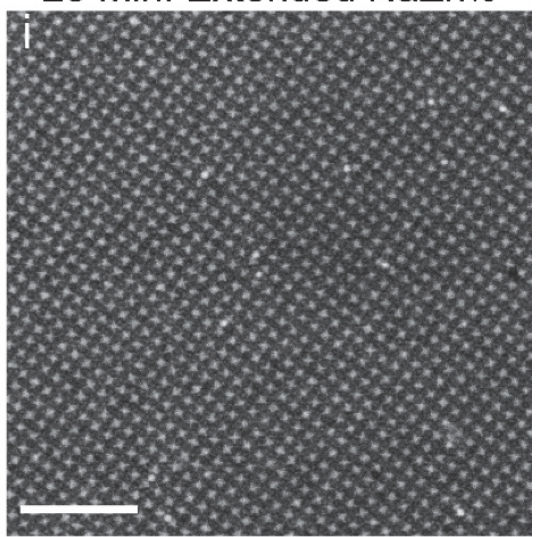

Figure S15. Structure evolution of spin-coated binary PGNC thin films of $5.4 \mathrm{~nm} \mathrm{PS}-\mathrm{Fe}_{3} \mathrm{O}_{4}(2.7$ kDa PS-PEHA) and $13.5 \mathrm{~nm}$ PS-Fe $\mathrm{O}_{4}\left(2.7 \mathrm{kDa}\right.$ PS-PEHA) upon $\mathrm{CHCl}_{3} \mathrm{SVA}$ at the PGNC volume fraction of $\varphi_{\mathrm{PGNC}}=0.44$. $(\mathrm{a}, \mathrm{b}) \mathrm{TEM}$ images of $\mathrm{Fe}_{3} \mathrm{O}_{4}$ PGNCs (c) Histograms of center-tocenter interparticle distances of PGNCs. (d-i) Representative SEM images of PGNC films (d) before and (e-i) after SVA for (e) $2 \mathrm{~min}$, (f) $5 \mathrm{~min}$, (g) $10 \mathrm{~min}$, (h) $15 \mathrm{~min}$ and (i) $25 \mathrm{~min}$. Scale bars: (a, b) $100 \mathrm{~nm},(\mathrm{~d}-\mathrm{i}) 200 \mathrm{~nm}$. 


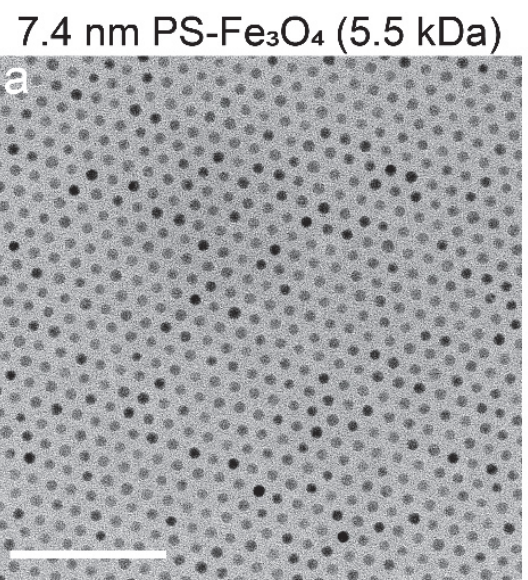

0 min: Random mixture

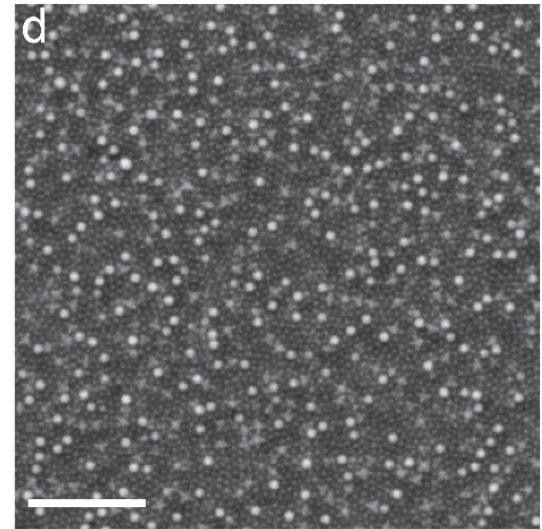

15 min: Continuous nucleation

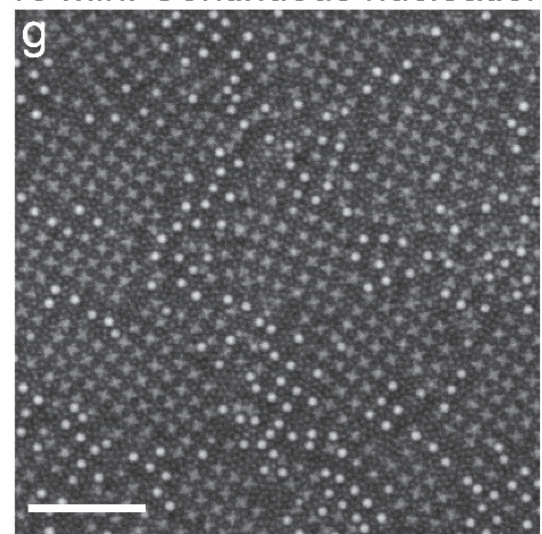

$16.8 \mathrm{~nm} \mathrm{PS}-\mathrm{Fe}_{3} \mathrm{O}_{4}(8.2 \mathrm{kDa})$

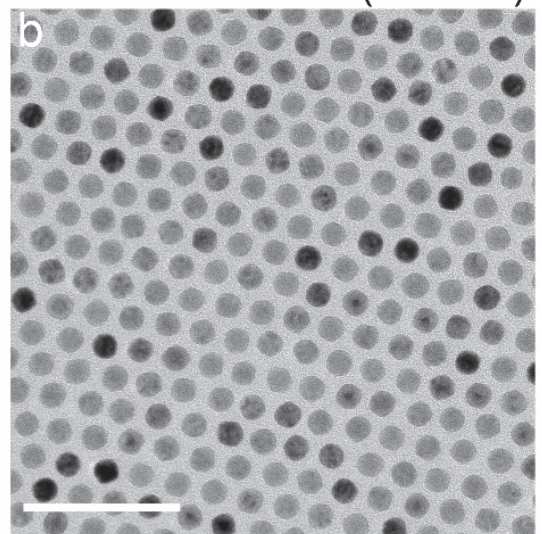

5 min: Spinodal-like

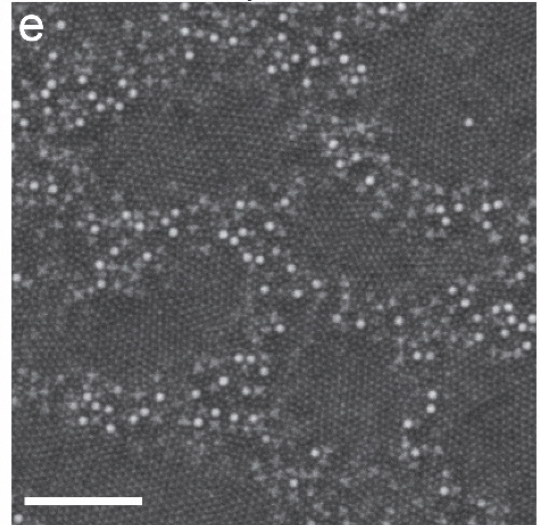

25 min: Ripening

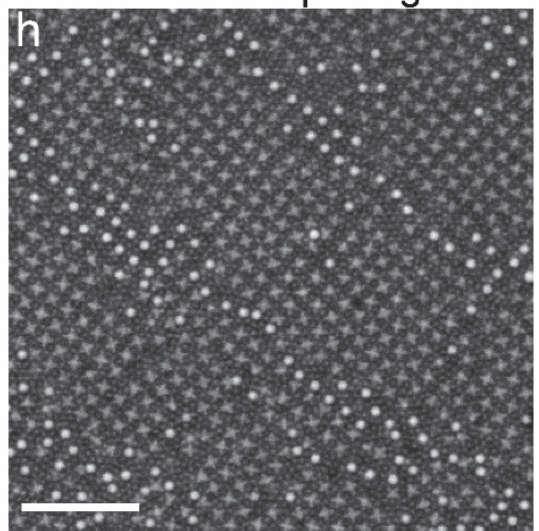

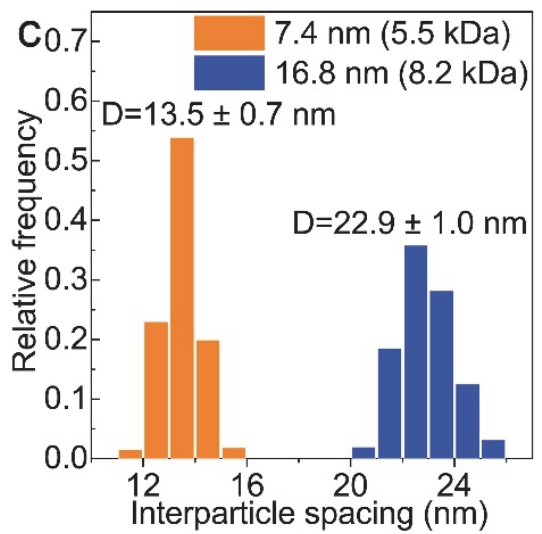

10 min: Initial nucleation

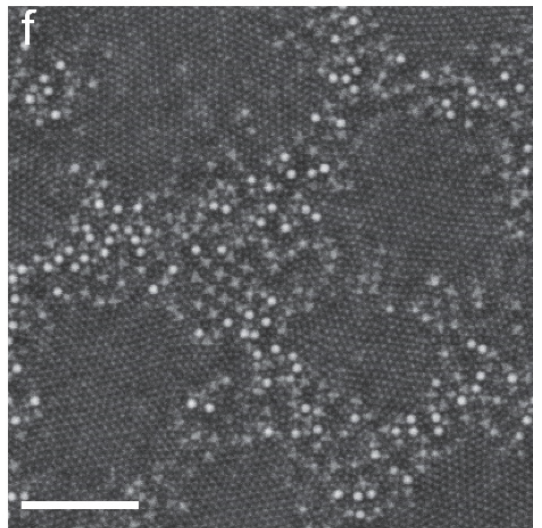

35 min: Extended $\mathrm{NaZn}_{13}$

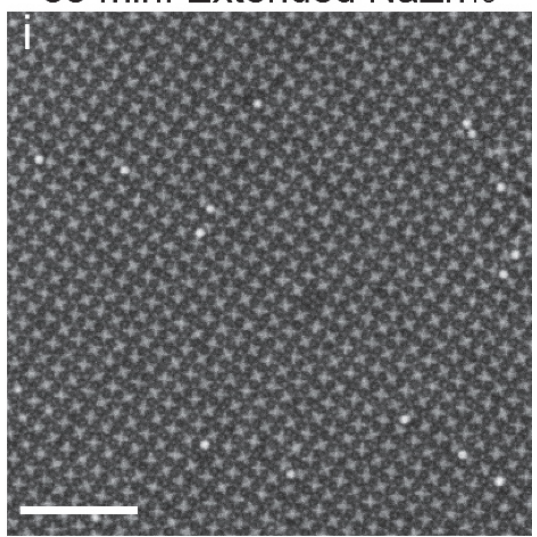

Figure S16. Structure evolution of spin-coated binary PGNC thin films of $7.4 \mathrm{~nm} \mathrm{PS}-\mathrm{Fe}_{3} \mathrm{O}_{4}$ (5.5 $\mathrm{kDa}$ PS-PEHA) and $16.8 \mathrm{~nm} \mathrm{PS-Fe} \mathrm{O}_{4}\left(8.2 \mathrm{kDa}\right.$ PS-DETA) upon $\mathrm{CHCl}_{3} \mathrm{SVA}$ at $\mathrm{PPGNC}=0.44$. (a, b) TEM images of $\mathrm{Fe}_{3} \mathrm{O}_{4}$ PGNCs. (c) Histograms of center-to-center interparticle distances of PGNCs. (d-i) Representative SEM images of PGNC films (d) before and (e-i) after SVA for (e) 5 min, (f) $10 \mathrm{~min}$, (g) $15 \mathrm{~min}$, (h) $25 \mathrm{~min}$ and (i) $35 \mathrm{~min}$. Scale bars: (a, b) $100 \mathrm{~nm}$, (d-i) $200 \mathrm{~nm}$. 
8.7 nm PS-Fe $\mathrm{O}_{4}(2.7 \mathrm{kDa}) \quad 20.6 \mathrm{~nm} \mathrm{PS}-\mathrm{Fe}_{3} \mathrm{O}_{4}(2.7 \mathrm{kDa})$
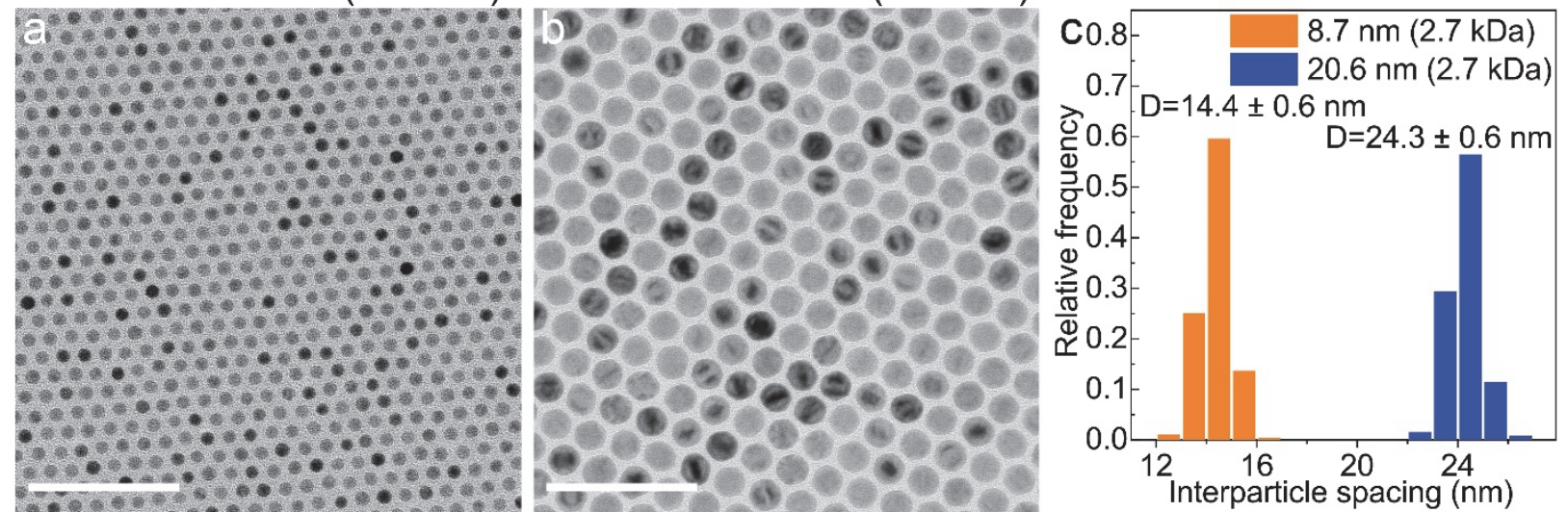

0 min: Random mixture

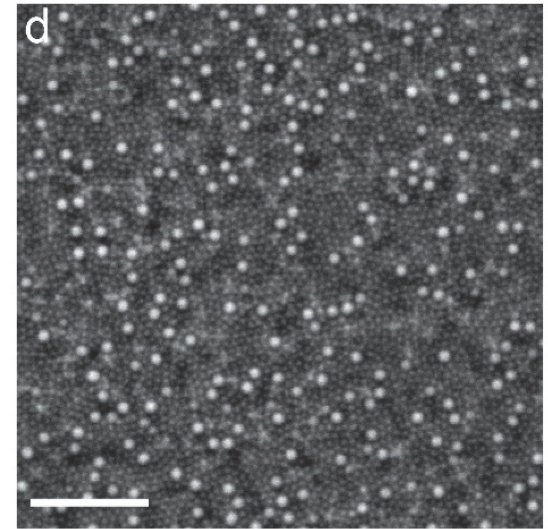

40 min: Continuous nucleation

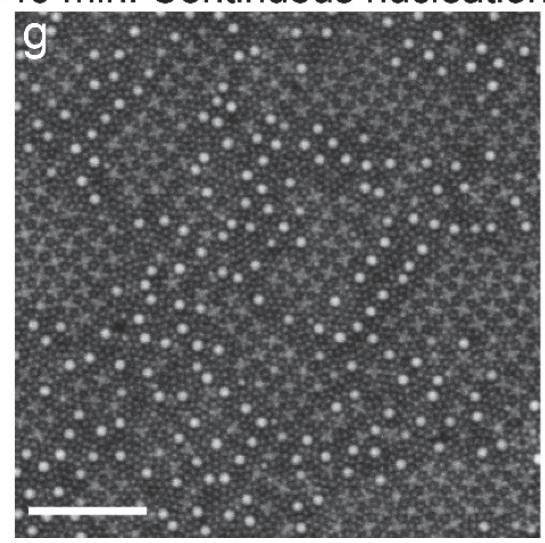

15 min: Spinodal-like

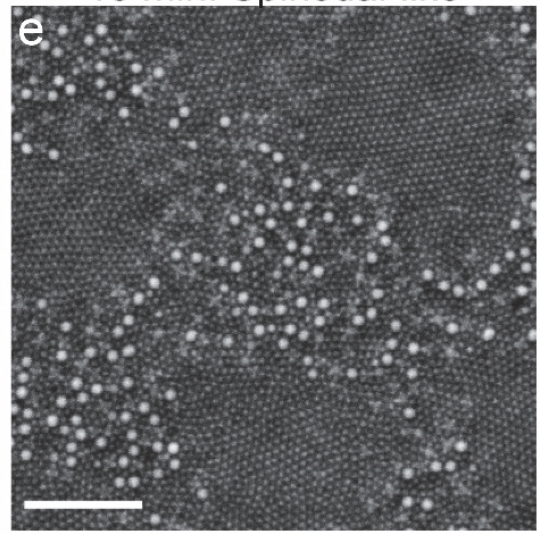

60 min: Ripening

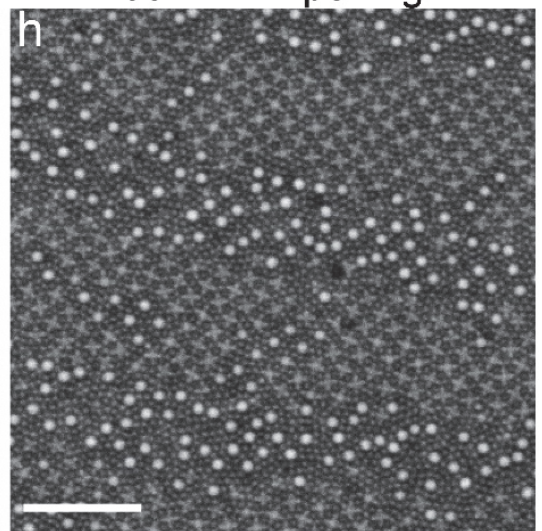

25 min: Initial nucleation

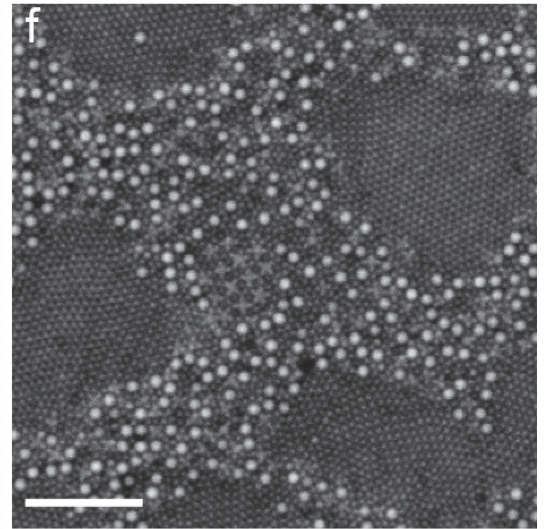

80 min: Extended $\mathrm{NaZn}_{13}$

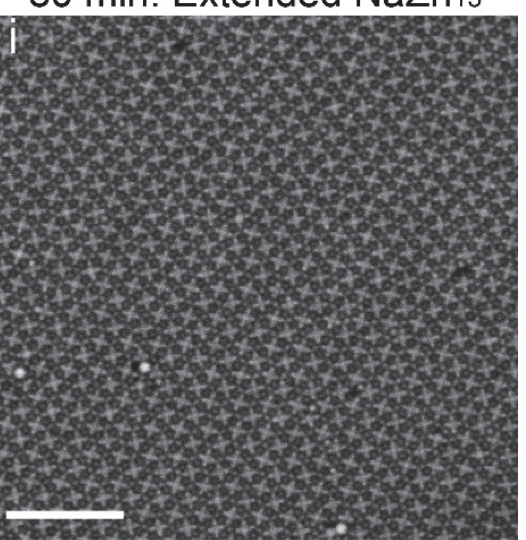

Figure S17. Structure evolution of spin-coated binary PGNC thin films of $8.7 \mathrm{~nm} \mathrm{PS-Fe} \mathrm{O}_{4}(2.7$ kDa PS-PEHA) and $20.6 \mathrm{~nm} \mathrm{PS-Fe} \mathrm{O}_{4}(2.7 \mathrm{kDa} P S-P E H A)$ upon $\mathrm{CHCl}_{3} \mathrm{SVA}$ at $\varphi$ PGNC = 0.44 (a, b) TEM images of $\mathrm{Fe}_{3} \mathrm{O}_{4}$ PGNCs. (c) Histograms of center-to-center interparticle distances of PGNCs. (d-i) Representative SEM images of PGNC films (d) before and (e-i) after SVA for (e) $15 \mathrm{~min}$, (f) $25 \mathrm{~min}$, (g) $40 \mathrm{~min}$, (h) $60 \mathrm{~min}$ and (i) $80 \mathrm{~min}$. Scale bars: (a, b) $100 \mathrm{~nm}$, (d-i) $200 \mathrm{~nm}$. 


\section{Supplementary References}

(1) Jakubowski, W.; Kirci-Denizli, B.; Gil, R. R.; Matyjaszewski, K. Polystyrene with Improved Chain-End Functionality and Higher Molecular Weight by ARGET ATRP. Macromol. Chem. Phys. 2008, 209, 32-39.

(2) Chen, J.; Fasoli, A.; Cushen, J. D.; Wan, L.; Ruiz, R. Self-Assembly and Directed Assembly of Polymer Grafted Nanocrystals via Solvent Annealing. Macromolecules 2017, 50, 9636-9646.

(3) Park, J.; An, K.; Hwang, Y.; Park, J. G.; Noh, H. J.; Kim, J. Y.; Park, J. H.; Hwang, N. M.; Hyeon, T. Ultra-Large-Scale Syntheses of Monodisperse Nanocrystals. Nat. Mater. 2004, 3, 891895.

(4) Ilavsky, J. Nika: Software for Two-Dimensional Data Reduction. J. Appl. Cryst. 2012, 45, 324328.

(5) Jiang, Z. GIXSGUI: A Matlab Toolbox for Grazing-Incidence X-ray Scattering Data Visualization and Reduction, and Indexing of Buried Three-Dimensional Periodic Nanostructured Films. J. Appl. Cryst. 2015, 48, 917-926.

(6) Müller-Buschbaum, P.; Gutmann, J. S.; Wolkenhauer, M.; Kraus, J.; Stamm, M.; Smilgies, D.; Petry, W. Solvent-Induced Surface Morphology of Thin Polymer Films. Macromolecules 2001, 34, 1369-1375.

(7) Phillies, G. D. J. Universal Scaling Equation for Self-Diffusion by Macromolecules in Solution. Macromolecules 1986, 19, 2367-2376.

(8) Kohli, I.; Mukhopadhyay, A. Diffusion of Nanoparticles in Semidilute Polymer Solutions: Effect of Different Length Scales. Macromolecules 2012, 45, 6143-6149.

(9) Huang, J.; Chen, X.; Bai, P.; Hai, R.; Sun, C.; Xu, T. 45\% Periodicity Reduction in Nanocomposite Thin Films via Rapid Solvent Removal. Macromolecules 2019, 52, 1803-1809.

(10) Voudouris, P.; Choi, J.; Dong, H.; Bockstaller, M. R.; Matyjaszewski, K.; Fytas, G. Effect of Shell Architecture on the Static and Dynamic Properties of Polymer-Coated Particles in Solution. Macromolecules 2009, 42, 2721-2728. 
(11) Lin, C. C.; Griffin, P. J.; Chao, H.; Hore, M. J. A.; Ohno, K.; Clarke, N.; Riggleman, R. A.; Winey, K. I.; Composto, R. J. Grafted Polymer Chains Suppress Nanoparticle Diffusion in Athermal Polymer Melts. J. Chem. Phys. 2017, 146, 203332.

(12) Grabowski, C. A.; Mukhopadhyay, A. Size Effect of Nanoparticle Diffusion in a Polymer Melt. Macromolecules 2014, 47, 7238-7242.

(13) Tuteja, A.; Mackay, M. E.; Narayanan, S.; Asokan, S.; Wong, M. S. Breakdown of the Continuum Stokes-Einstein Relation for Nanoparticle Diffusion. Nano Lett. 2007, 7, 1276-1281. 